\title{
Caracas: Un intento frustrado de continuidad de las bienales hispanoamericanas de arte (I)
}

\author{
Miguel Cabañas Bravo
}

\section{LA PARTICIPACIÓN EN LAS BIENALES CELEBRADAS}

Las Bienales Hispanoamericanas de Arte, certamen internacional convocado oficialmente por el Estado español e inscrito en su «política de la Hispanidad", se desarrolló durante la década de 1950, precisamente durante la cual también la plástica venezolana, gracias a la profundización en las investigaciones constructivistas, es decir, gracias al arte cinético y trabajos ópticos, comenzó a conseguir aceptación y audiencia internacional.

Si el momento, políticamente, correspondía en España al régimen del 18 de julio y sus intenciones de apertura y afirmación en el contexto inter-: nacional; en Venezuela, aunque a principios de la década, cuando se celebró la primera edición de estas Bienales, ostentaba la presidencia de la República Fernando Suárez Flamerich, en realidad, la mayor parte del decenio la ocupó el dictador Marcos Pérez Jiménez, quien se adjudicó fraudulentamente el triunfo de las elecciones de diciembre de 1952, permaneciendo en el poder hasta la caída del régimen en 1958. Fue para Venezuela, con todo, una época de crecimiento, inversión extranjera y expansión empresarial, consecuente con el ritmo de modernización y desarrollo que comenzara en tiempos del mandato del presidente Eleazar López Contreras (1936-1941), durante el cual se produjo la nacionalización de la industria petrolera en México (1938) afectando provechosamente a Venezuela, que rápidamente recibió buena parte de las inversiones y personal técnico de las empresas internacionales expropiadas, dando lugar a una prosperidad que iba a durar hasta los inicios de los años setenta ${ }^{\prime}$.

Véase Carlos A. BALE: “Venezuela: El triste caso de un gobierno rico y un pueblo paupérrimo», en Barry, B. LEVINE (Compilador): El desafío neoliberal, Bogotá, Ed. Norma, 1992, págs. 283-306. 
En lo que respecta a la evolución del arte venezolano hasta mediados del siglo XX, cuando se inauguraban las citadas Bienales, señalemos que la historia de su renovación artística arranca de 1912, cuando se crea el Círculo de Bellas Artes, que dio un gran giro reactivador y eficaz a la vida cultural caraqueña, al que vinieron a unirse otras circunstancias que ayudaron a la actualización artística ${ }^{2}$, aunque el tiempo pronto hizo de este avance academia de paisajistas. Tras la segunda guerra mundial, la escena artística venezolana, como la social y la económica, comenzó a hacerse más dinámica, apareciendo jóvenes e inquietos artistas que, en busca de nuevas alternativas, se unieron para exponer formando el grupo Barraca de Maripérez, que incluía a Pedro León Zapata, Sergio González, Celso Pérez, Enrique Sardá, Raúl Infante, Luis Guevara Moreno y Perán Erminy, aunque pronto lo abandonaron en favor de México y París; como ocurrió con otros artistas que fueron surgiendo en estos momentos, tal como el escultor Francisco Narváez, los pintores Marcos Castillo, A. E. Monsanto, Alejandro Otero, etc., quienes fueron siendo atraidos por la capital gala y los nuevos lenguajes, con pronta dirección hacia la experimentación abstracta y constructivista ${ }^{3}$.

2 Ya desde fines del siglo XIX venía trabajando un grupo de pintores historicistas y paisajistas (Martín Tovar, Cristóbal Rojas, Arturo Michelena y Antonio Herrera) de cierta corrección; a lo que se sumó la presencia del rumano Samys Mützner y el ruso Nicolás Ferdinandov, pintores que introdı! jeron una nueva sensibilidad hacia el color y su intensidad, y, especialmente, fue importante la incorporación de ciertos pintores (Armando Reverón, Rafael Monasterios, Federico Brandt) que el primer conflicto bélico mundial devolvió a Venezuela portando la visión de las nuevas corrientes europeas; actuó de enlace entre unos y otros otra serie de pintores (entre ellos Manuel Cabré, Tito Salas y, pese a su amplia adcripción a París, Emilio Boggio con su impresionismo tardio) que asimismo contribuyeron a crear un clima progresivamente más propicio para el desarrollo del avance artístico. El Círculo de Bellas Artes fue, esencialmente, el que puso en contacto a esta serie de pintores y abrió las puertas a criterios actualizados, resultando de ello la llamada Escuela de Caracas, esencialmente volcada hacia el paisaje y que repitió una y otra vez la imagen y luminosidad del valle de Caracas y el monte Avila que lo domina. Con todo, escapó bastante a este esquema el más destacado y peculiar de estos artistas que, sin duda, fue Armando Reverón (18891954), quien pasó algún tiempo formándose en España -y que, adelantemos, estuvo representado en las dos últimas Bienales Hispanoamericanas celebradas-. Predispuesto para pintar ofro tipo de paisaje, abandonó pronto las fórmulas académicas y en 1921 salió de Caracas para instalarse en Macuto, en la costa del mar, donde - de una forma muy personal y un tanto excéntrica - vivió toda su vida influido por su paisaje y su luz. Precisamente la luz peculiar del trópico fue lo verdaderamente importante en su obra, que pasó por tres épocas: la azul, la blanca y la parda o sepia. Si en la primera buscó la luz de los crepúsculos, en la última buscó el tema hu* mano, sin duda, fue la segunda, de predominio del color blanco, la más interesante de todas, consiguiendo con un blanco casi puro integrar los colores det espectro y crear una luminosidad sorprendente. (Véase sobre Reverón: Alfredo BoulTon: Reverón, Caracas, Ediciones Macanao, 1979; Miguel C. Arrollo y otros: Armando Reverón (1889-1954): Exposición Antológica, Madrid, MNCA Reina Sofía, 1992, y Rina CARVAJAL: «Armando Reverón» en Latin American Artists of the Twentieth Century, Nueva York, MoMa, 1993, págs. 40-45.

3 Sin embargo, aunque en menor medida, también tentó a los artistas venezolanos tanto el muralismo y sentido social del arte mexicano (caso del pintor León Castro, que pronto asoció el interés por lo onírico), como el surrealismo, destacando Héctor Poleo (precisa y paradójicamente el 
A fines de los años cuarenta, pues, se hacía perceptible que el arte avanzado venezolano se había distribuido en dos focos: Caracas y París. En el primero, en 1948, varios artistas fundaron el llamado Taller Libre de Arte - donde luego veremos originarse una de las «contrabienales» que se opusieron a la Bienal madrileña-, centro surgido con la intención de distanciarse de la preponderancia de la escuela caraqueña de paisajistas y servir de plataforma al debate de nuevas ideas y a la experimentación de novedades. En París, segundo de los focos, hacia 1949 una serie de artistas y escritores venezolanos creó el grupo «Los Disidentes», entre cuyos fundadores estuvieron Alejandro Otero, Luis Guevara Moreno, Pascual Moreno, Mateo Manaure, Carlos González Bogen, Narciso Debourg, Perán Erminy, Rubén Nuñez, Dora Hersen, Aimée Battistini y J.R. Guillén Pérez, a los que luego se añadirán, además de los escritores Rafael Zapata, Miguel Arroyo y el cineasta César Enríquez, los artistas Armando Barrios, Oswaldo Vigas, Alirio Oramas, Régulo Pérez, Genaro Moreno y Omar Carreño. De grandes inquietudes y pronta dirección abstracto-geométrica, el grupo publicó en esta capital la combativa Revista los disidentes, que atacó duramente el conservadurismo artístico y cultural venezolano. Además, haciendo más interesante este núcleo, también por París pasaron otros artistas más o menos relacionados con este grupo e interesados por los problemas constuctivos y los aspectos visuales de las artes, como es el caso de Jesús Rafael Soto, Víctor Valera, Carlos Cruz Díez, etc., que pronto iban a adquirir gran importancia con el cinetismo.

La mayor parte de estos artistas, empero, comenzaron a regresar a Venezuela a partir de mediados de la década de los cincuenta, cuando la abstracción y la figuración ya habían tenido su enfrentamento y las nuevas corrientes empezaban a menudear. Por entonces, además, seguía aún en marcha la construcción de la Ciudad Universitaria de Caracas, realizada en varias etapas desde mediados de los años cuarenta hasta mediados de los años sesenta y con la que el arquitecto Carlos Raúl Villanueva, en su propósito de integración de las artes, había sabido crear un acertado ambiente artístisco, llamando a colaborar en ella a artistas venezolanos como Valera, Soto, Omar Carreño, Barrios, Oswaldo Vigas, Manaure, Pascual Navarro, Francisco Nárvaez, Alejandro Otero, González Bogen, León Castro, Héctor Poleo, junto a otros americanos y europeos como Jean

único artista venezolano que obtuvo algún galardón en las Bienales Hispanoamericanas), quien tras unos comienzos formativos con el muralismo mexicano, pasó a París, derivando del tema politico y social a cierto ingenuismo emparentado con lo surrealista; ingenuismo, por otro lado, también visible en Bárbaro Rivas. 
Arp, Henri Laurens, Baltasar Lobo, Fernand Léger, Alexander Calder, Antoine Pevsner, Wifredo Lam o Víctor Vasarely ${ }^{4}$.

Este panorama artístico, con su revolucionario desarrollo de las experiencias constructivistas desde comienzos los años cincuenta, representa la parte más relevante del arte venezolano que pudiera haber concurrido a las Bienales Hispanoamericanas, aunque, en la práctica, la realidad resultó mucho más prosaica y revuelta, acentuando el hecho la misma intervención de la política y sus intereses. Asunto este último que, como con buena parte de la participación de los países extranjeros, fue lo que primó en la aportación de Venezuela a estas Bienales, un certamen, por otro lado, organizado de cara al exterior con mayor carga e intereses políticos y diplomáticos que propiamente artísticos.

Es decir, estas Bienales fueron organizadas por el Instituto de Cultura Hispánica, entidad autónoma pero a la vez dependiente del Ministerio de Asuntos Exteriores español, el cual, mientras el Instituto movilizó a los fines del certamen a toda la red de asociaciones filiales y adheridas que poseía en España y América, proporcionó los créditos y la importante gestión de los embajadores y representantes diplomáticos españoles para conseguir oficialidad, patrocinio y participación artística de los países invitados. Ambas instituciones, pues, hicieron posible la organización y celebración de las Bienales, pero también las convirtieron en un frecuente instrumento de uso político inscrito en la mirada española hacia el exterior. En otras palabras, la concepción y celebración de este certamen pasa por ser una pieza más de actuación de la citada "política de la Hispanidad», que -dirigida a los países iberoamericanos para favorecer, mediante el prestigio de lo cultural común y vinculante, la introducción de finalidades político-económicas- fue, junto a las aproximaciones al Vaticano, la búsqueda de reconocimiento por Estados Unidos y las miradas amigables hacia el mundo árabe, una de las direcciones más importantes y destacadas de la política exterior de la España del momento.

Llegaron a celebrase, pues, tres ediciones de este certamen internacional dirigido a la comunidad de países hispánicos -incluidos como

4 Sobre el desarrollo del arte venezolano véase Alfredo BoulTon: Historia de la pintura en Venezuela, Caracas, Ed. Arte, 1968; Damián BAyón: Aventura plástica de Hispanoamérica, México D.F., FCE, 1974, págs. 206 y ss,; Bélgica Rodríguez: La pintura abstracta en Venezuela: 19451965, Caracas, Gerencia de Relaciones Públicas de Maraven, 1980; Roberto GuEvara: «Artes visuales en Venezuela, 1950-1980", en Damián BAYón (ed.): Arte moderno en América Latina, Madrid, Taurus, 1985, págs. 210 y ss., y Aracy AmARAL: «Abstract Constructivist Trends in Argentina, Brazil, Venezuela, and Colombia", en Latin..., op. cit., págs. 86-99. 
«invitados de honor» Portugal, Brasil, Filipinas, Estados Unidos y Canadá-. La Primera y con la que daba comienzo se celebró en Madrid, entre los meses de octubre de 1951 y febrero de 1952, con una prolongación antológica en Barcelona entre marzo y abril del último año. La Segunda, patrocinada por las dictaduras franquista y batistiana, se llevó a La Habana, donde fue celebrada entre mayo y septiembre de 1954, siendo luego seguida de varias exposiciones antológicas presentadas en diferentes países americanos, entre ellos Venezuela. Finalmente, la Tercera regresó a España, siendo celebrada en Barcelona entre septiembre de 1955 y enero de 1956, sucediéndole una exposición antológica en Ginebra entre marzo y mayo de ese último año.

A estas tres ediciones, de características bastante semejantes ${ }^{5}$, sucedieron -haciendo depender cada vez más su realización del abrigo de las políticas latinoamericanas- dos importantes proyectos de celebrar la Cuarta Bienal Hispanoamericana: un primero que, entre 1956 y 1958, se propuso celebrarla en Caracas, como veremos más adelante, y un segundo que, entre 1958 y 1961 y uniendo su patrocinio a las reuniones de la Organización de Estados Americanos (OEA), se propuso celebrarla en Quito. Ambos proyectos, pese al apoyo presidencial del primero y a lo avanzado que llegó a estar el segundo, finalmente resultaron fracasados e hicieron que estas tormentosas Bienales Hispanoamericanas y su

\footnotetext{
5 En cuanto a estas características, digamos que inspiradas formalmente en las de Venecia -pese a las particularidades - y con nacimiento paralelo a las de Sao Paulo (inauguradas pocos días después de las Hispanoamericanas), no se dirigieron, como las venecianas, hacia e! reconocimiento del vanguardismo heroico ni, como las paulistas, hacia el nuevo vanguardismo, sino que se situaron en una línea más ecléctica y con especiales consideraciones hacia valores y contenidos hispánicos, consecuencia de la misma vía de política iberoamericanista en que nacían. Aparte, pues, de su eclecticismo artístico, la dirección iberoamericana y su carácter oficial, estas ediciones se caracterizaron por una reglamentación muy similar —aunque reelaborada en cada una-; un peculiar sistema de selección de artistas y obras que combinaba la invitación personal y un procedimiento de "exposiciones preparatorias"; la división del concurso en cuanto secciones principales: 1. Arquitectura y Urbanismo. 2. Escultura. 3. Pintura y 4. Dibujo, Grabado y Acuarela (en las dos últimas Bienales además se añadió una sección de Arte Decorativo, que en cada edición debía corresponder a una especialidad diferente, dedicándose a la Cerámica en La Habana y a la Joyería y Esmaltes en Barcelona, proyectándose Tejidos Artísticos para una cuarta edición); y la presentación, paralelamente al concurso, de exposiciones retrospectivas y monográficas de diversos artistas, junto a otras variadas actividades artísticas de realce del certamen. En otro plano, también caracterizó singularmente a estas Bienales que antes y durante su celebración, principalmente debido al rechazo que inspiraba el régimen político que las creara, fueron objeto de la repulsa de los artistas, quienes la manifestaron en escritos y a través de diversas actividades, entre las que destacan la celebración de exposiciones «contrabienal» y «antibienal». No obstante, casi como contestación a esta actividad adversa y a la vez en busca de propaganda y nuevos mercados, también las caracterizó la celebración tras la clausura de la edición de muestras antológicas de la misma en otros emplazamientos.
} 
Secretaría Permanente, dirigidas por el poeta Leopoldo Panero hasta su muerte (1962), fueran sustituidas en 1963 por las exposiciones de «Arte de América y España».

Pese a que en calidad artística merece destacarse especialmente la edición de Barcelona o, por ejemplo, en importancia para el escenario cubano y promoción en América del certamen, la de La Habana; sin duda, la más importante de las Bienales Hispanoamericanas celebradas fue -con especial relevancia y trascendencia para el panorama español- la prime$\mathrm{ra}^{6}$. Inaugurada con toda solemnidad y boato por el general Franco, acompañado de las altas jerarquías y el cuerpo diplomático acreditado, en la significativa fecha del 12 de octubre de 1951, Día de la Hispanidad y año

6 Entre algunos de los datos difundidos desde lo oficial, citemos que concurrieron a esta 1 Bienal 885 artistas de 21 paises, con un total de unas 1.750 obras a concurso, más 300 en salas especiales. Hubo exposiciones monográficas, entre otros, de Clará, Colom, Sunyer, Salvador Dalí, Cecilio Guzmán de Rojas y un grupo de «Precursores» (Beruete, Juan de Echevarría, Gimeno, Iturrino, Nonell, Pidelaserra, Regoyos y Solana). La Muestra ocupó más de 50 salas, repartidas entre el Museo de Arte Moderno - que fue desmontado para la ocasión-. La Socjedad de Amigos del Arte, el Palacio de Exposiciones, el Palacio de Cristal del Retiro y varias salas del Museo Arqueológico, y recibió a más de medio millón de visitantes. Se otorgaron cerca de cuarenta recompensas, correspondiendo los Grandes Premios instituidos por la Bienal en pintura a Benjamín Palencia, Daniel Vázquez Díaz y Cesáreo Bernaldo de Quirós, en escultura a Juan Rebull y en grabado a Alberto Guido. Por otro lado, en cuanto a su importancia, fue ésta la edición del certamen que puso en marcha su mecanismo de organización y funcionamiento, donde apareció su ecléctica definición estética, el enfoque de la dirección iberoamericanista a seguir y otra serie de configuraciones y problemas que luego se repetirán en las siguientes ediciones. Pero además, esta I Bienal se sitúa en la España de un momento clave socio-política y culturalmente, en un momento de trascendentes cambios, es decir, en el paso de la autarquía de los años cuarenta a la etapa más liberalizadora y cosmopolita de los cincuenta, que hizo funcionar al certamen -donde junto a los relevantes afanes de proyección y afirmación exterior con los que nacía concurrieron las intenciones de transformar una serie de valores y estructuras que habían protagonizado los años cuarenta - como eficaz bisagra entre dos importantes décadas y visiones del arte y la actuación artística oficial. De este modo, la I Bienal Hispanoamericana resultó un hito innegable del arte español contemporáneo, culminación del arte desarrollado en los años cuarenta y punto de arranque de un nuevo período; pues, gracias a la importancia dada a la proyección exterior, las intenciones renovadoras y la medida del amplio eclecticismo que hubo que emplearse como criterio estético y solución, fue, efectivamente, ocasión de reconocimiento y sanción oficial de una situación artística más amplia y diversa que la que hasta entonces el Estado se había empeñado en prestar atención y proteger. Dio así a contemplar oficialmente el certamen, entre amplia e innegable resonancia social, una extensa representación de todo el panorama artístico español que se habia ido desarrollando en los años cuarenta, incluyendo sus aún tímidas direcciones vanguardistas; pero el hecho que se aceptaran oficialmente las nuevas corrientes, con el arte abstracto en cabeza, abrió la puerta a violentas y trascendentes polémicas entre los artistas academicistas y de avanzada tras la que comenzó la escena artística española a revitalizarse, superando su retardamiento e iniciando su sincronización con la internacional. (Sobre la I Bienal y su alcance véase M. Cabañas Bravo: La Primera Bienal Hispanoamericana de Arte: Arte, política y polémica en un certamen internacional de los años cincuenta (2 vol.), Madrid, Editorial Universidad Complutense, 1992.) 
de conmemoración del quinto centenario del nacimiento de isabel la Católica y Cristóbal Colón, pronunció el discurso inaugural el nuevo ministro de Educación Nacional, Joaquín Ruiz Giménez, quien no perdió la ocasión para dejar clara la renuncia oficial a lograr, continuando con el «proteccionismo" del arte academicista, un arte propio del régimen e, insistiendo en la apertura y autonomía que debía conceder el Estado al Arte, sancionó oficialmente la admisión de las nuevas corrientes artísticas en la esfera oficial y señaló el rumbo de una nueva política artística española.

No obstante, en realidad la I Bienal venía ya precedida de más de un año de planteamientos, organización y celebración de exposiciones preparatorias de selección desde que antes del verano de 1950 se comenzara a idear su celebración. Y, como correspondía a un proyecto ampliamente volcado hacia el exterior, el Instituto de Cultura Hispánica, organizador esencial del certamen, empezó entonces por dirigirse a los representantes diplomáticos españoles acreditados en los paises americanos informándoles sobre el certamen que se preparaba y pulsando su opinión.

Es así como, los primeros contactos y relaciones de Venezuela con la Bienal Hispanoamericana tienen un inicio muy semejante al del resto de los países invitados, dándose, como en ellos, por la via diplomática. Así, mientras se redactaban en el citado Instituto unos Estatutos provisionales del certamen, en agosto de 1950, el director del organismo, Alfredo Sánchez Bella, dirigía unas cartas a los representantes diplomáticos españoles informándoles sobre el proyecto de la Bienal y señalándoles la necesidad de su intervención para organizar la selección artística y recabar ayuda material y respaldo oficial de cada uno de los gobiernos. Más tarde, en septiembre del mismo año, remitió Sánchez Bella a los mismos diplomáticos los Estatutos provisionales del certamen, con la finalidad de que los estudiaran y plantearan las objeciones que les parecieran pertinentes para proceder a la redacción de los definitivos ${ }^{7}$. Finalmente, a comienzos del mes de diciembre, volvía a dirigirse el director del Instituto a estos representantes enviándoles la reglamentación definitiva del certamen,

\footnotetext{
El tipo de dificultades que, en sus despachos con el ministro de Asuntos Exteriores español, hicieron resaltar buena parte estos representantes diplomáticos, incidieron, principalmente, en la indiferencia, cuando no en la hostilidad politica que se mostraría hacia una iniciativa cultural proveniente del régimen español, así como las grandes dificultades que habría para conseguir una cooperativa oficial y económica de los gob iernos extranjeros; es decir, esencialmente evidenciaron problemas políticos y económicos, sin apenas reparar en los artísticos, donde una de las mayores dificultades estribaba en conseguir comisiones de selección con criterios actualizados acerca del arte.
} 
cuyo «actual texto - les decía - tiene una mayor flexibilidad y una orientación más objetiva y sencilla que procura atraer a todos y no excluir a nadie, pues sabida es la escrupulosa suceptibilidad profesional de los artistas plásticos», y una carta dirigida al respectivo presidente de cada república - que estos diplomáticos le debían hacer llegar-, en la que invitaba oficialmente al país a tomar parte en el certamen y solicitaba la ayuda y patrocinio presidencial para el mismo. Iban precedidos estos Estatutos y la carta a los presidentes de la que, a la vez, dirigía a los propios representantes diplomáticos españoles dándoles detalles e instrucciones sobre el certamen, precisándoles donde se necesitaba de su ayuda y, finalmente, orientándoles sobre su criterio: «me permito indicarle — señalaba sobre éste - que el criterio estético que ha inspirado nuestro propósito y el que mejor coincide con la realidad artística hispanoamericana, es el que discretamente podríamos denominar libre ó moderno, esto es, actual, aunque sin exageraciones y, desde luego, sin exclusivismos de ninguna clase. Pero queremos en lo posible evitar el amaneramiento académico y dar paso a un Arte auténtico y viviente... Creo sinceramente que además del éxito artístico que esta Exposición Hispanoamericana debe y puede tener, comporta también, y de una manera muy señalada, la clara posibilidad de un inteligente triunfo político, pues pocos instrumentos estimo tan propicios como éste para la armonía y desinteresada agrupación de los pueblos hispánicos y de sus respectivas culturas nacionales» ${ }^{8}$.

De este modo, el embajador español en Caracas, Teodomiro de Aguilar y Salas, a mediados de enero del año siguiente, informaba al ministro español de Asuntos Exteriores de su entrevista con su homónimo venezolano, Luis Emilio Gómez Ruiz, quien se había mostrado participativo y ofrecido su adhesión sobre el proyecto de la Bienal ${ }^{\circ}$. A partir de este momento, el diplomático continuó informando al ministro español sobre las adhesiones de personalidades y de las favorables y buenas impresiones

\& Sobre esta correspondencia del director del ICH en torno a la organización de la I Bienal, véase lbídem, págs. 444-497 y 701 y ss.

9 En la entrevista, decía el embajador, había tratado de algunos asuntos referentes al homenaje a Isabel la Católica, el Congreso Hispano-Luso de Derecho Internacional y la I Bienal Hispanoamericana que se celebrarían ese año en España y en todos ellos el ministro venezolano se había mostrado participativo y ofrecido su adhesión. Respecto a la última el embajador indicaba, además, que hacía tiempo la Embajada venía practicando gestiones y que Gómez Ruiz le había demostrado su interés por la Bienal, respecto a la cual le había enviado una Nota verbal el 2 de enero, manifestado que entregaría personalmente la carta dirigida por el director del ICH al presidente de la Junta de Gobierno de los EE.UU. de Venezuela. (Telegrama Urgente número 6 del embajador de fecha 16 de enero de 1951. Archivo de Asuntos Exteriores -en adelante citado con las siglas AMAE-, Leg. R-4.263, Exp. 22.) 
que se tenían sobre las gestiones emprendidas y la colaboración oficial requerida ${ }^{10}$, lo que asimismo haría al Instituto de Cultura Hispánica ver con optimismo la participación venezolana ${ }^{11}$.

10 Ya en el telegrama citado el diplomático prometía ampliar la información en un Despacho posterior que, efectivamente, remitía siete días más tarde añadiendo que las impresiones reco gidas de las diversas personas a las que se había solicitado su concurso se resumían así: "Señor Ministro de Relaciones Exteriores, señores don V. Cedillo, don Germán Borregales, don Manuel Otero - director del Museo de Bellas Artes-, don Castro Fulgencio López — vicepresidente de la Asociación de Escritores Venezolanos-, don Juan Rhol y don Ramón Díaz Sánchez - director de Cultura y Bellas Artes--; todos los nombrados han ofrecido prestar su apoyo. En breve, espero quedarán ultimadas las gestiones que se practican y en marcha la puesta en práctica del fin que se persigue" (Despacho número 45 de fecha de 23 de enero de 1951. AMAE, Leg. R-4.263, Exp. 22). Antes de mediar febrero, en un nuevo Despacho informaba que el ministro de Relaciones Exteriores venezolano había entregado al presidente de Venezuela la carta del director del ICH, así como refería la propaganda sobre la Bienal realizada en los diarios de Caracas por la Embajada española y comunicaba que, según le había manifestado el director de Cuitura del Ministerio de Educación venezolano, «todavía no se ha tomado una resolución definitiva sobre la participación de Venezuela, en espera de ciertos datos de tipo económico que se tienen solicitados. Para uno de estos días — también ha índicado- tiene convocada una reunión de artistas para tratar del mismo asunto" (Despacho número 99 de fecha de 13 de noviembre de 1951). Adjuntaba al mismo copia de la Nota número IE.B 288 de fecha de 10 de febrero de 1951, que le había dirigido el ministro de Relaciones Exteriores de Venezuela sobre la entrega de la carta al presidente venezolano. AMAE, Leg. R-4.263, Exp. 22). No obstante, a comienzos de marzo el embajador español pedía con urgencia información sobre el desplazamiento de la inauguración del certamen de mayo a octubre (Telegrama número 25 expedido el 6 de marzo de 1951; la Orden comunicada por telegrama número 19 expedido el 13 de marzo de 1951 le señalaba que, efectivamente, la fecha de apertura de la Bienal había sido desplazada al 12 de octubre para hacerla coincidir con la fiest a de la Hispanidad. AMAE, Leg. R-4.263, Exp. 22) y, a pesar del aplazamiento, a comienzos de abril remitía en un nuevo Despacho, para hacerse llegal al director del $1 \mathrm{CH}$, la contestación del Ministerio de Relaciones Exteriores venezolano sobre la carta enviada por éste al presidente venezolano, cuyo contenido, decía el embajador, «viene a confirmar la buena impresión que sobre la participación de Venezuela vengo dando a V.E. como consecuencia de la favorable acogida que la celebración de la referida Exposición ha merecido y merece entre cuantos organismos y personalidades he tratado y trato de dicho asunto, especialmente cerca de este Ministerio de Relaciones Exteriores, quien, desde el primer momento, la ha acogido con todo interés y simpatía". (Despacho número 242 de fecha de 10 de abril de 1951. Adjunto al mismo enviaba traslado de la Nota número IE.B 669 de fecha de 9 de abril de 1951 que Rafael Gallego Medina, encargado del Ministerio de Relaciones Exteriores de Venezuela, dirigía al embajador español anexando «la respuesta - le decía - que, por instrucciones del señor presidente de la Junta de Gobierno, he dirigido al señor Alfredo Sánchez Bella, director del Instituto de Cultura Hispánica de Madrid, en la cual informó al mencionado señor Sánchez Bella que Venezuela se propone colaborar en la mejor forma posible al éxito de la Exposición Bienal Hispano-Americana de Arte que se celebrará en la capital de España durante la primavera de este año"; AMAE, Leg. R-4.263, Exp. 22.)

Esta buena impresión en el ICH se desprendía ya del informe que a finales de febrero remitía Leopoldo Panero al director sobre la marcha de las gestiones con los diferentes países, señalando que las de Venezuela llevaban un «carácter regular y activo" (Informe interior fechado el 23 de febrero de 1951. AMAE, Leg. R-4.263, Exp. 22). Más tarde, la revista del Instituto Correo Literario, informaba de que en este país continuaban realizándose los preparativos para la celebración de la Exposición preparatoria de la Bienal, «teniendo que destacarse aquí las importantes gestiones que lleva a cabo el director de Cultura del Ministerio de Educación Nacional, señor Díaz 
Sin embargo, este optimismo pronto bajó de tono, pues ya mediado el mes de junio, el embajador español comunicaba al ministro en un despacho confidencial que había recibido una nota del ministro venezolano de Relaciones Exteriores donde le indicaba la declinación de la invitación hecha a su país para tomar parte en la Bienal, repentino cambio de actitud que el embajador español atribuía a motivos económicos, de descordinación de criterios y, relevantemente, políticos ${ }^{12}$. Con todo, Teodomiro de Aguilar no se dio por desanimado y continuó las gestiones para conseguir la participación venezolana, logrando dejar sin efecto el acuerdo del ministerio venezolano y poner en marcha la designación de un Jurado seleccionador del envío a Madrid ${ }^{13}$.

A partir de aquí, las gestiones para la selección de los artistas venezolanos comenzaron a ser más rápidas, apareciendo a comienzos de julio en la prensa caraqueña un aviso oficial de la Dirección de Cultura y Bellas

Sánchez, a fin de que la Exposición que ha de celebrarse en Caracas tenga el grado de interés que, naturalmente caracteriza a las exposiciones nacionales de esta clase"; añadía también que, "a juzgar por las comunicaciones recibidas en la Secretaría de la Bienal, este máximo certamen artístico ha despertado grandisimo interés en los círculos culturales venezolanos, y aquí se tiene la impresión de que su aportación será de gran importancia» [C. (Campoy): «Noticiario de la Bierial. Panamá. Venezuela", Correo Literario, número 23, Madrid, 1 de mayo de 1951, pág. 12].

12 En el sustancioso análisis que hacía el embajador aventurando las posibles razones de esta resolución, hablaba de "cuestiones relacionadas con el orden económico; es también posible que se haya podido tropezar con dificultades dada la poca coordinación de los servicios entre sí, $y$, por ende, la anti-tesis en no pocas ocasiones de criterios respectivos", añadiendo «la muy posible pasividad en el asunto del actual director de Cultura del Ministerio de Educación Nacional don Ramón Díaz Sánchez, que ejerce una indiscutible influencia en dicho Departamento en orden a los servicios que le están encomendados" y que en los antecedentes sobre el mismo que se le habían suministrado constaba como "político de la fracción de extrema izquierda". (Despacho Confidencial número 393 de fecha de 19 de junio de 1951. AMAE, Leg. R-4.263, Exp. 22.)

13 Así, informaba a comienzos de julio: "Desde que el 19 de junio próximo pasado elevé a conocimiento de V.E., en mi Despacho número 393, el contenido de la Nota recibida de este señor Ministro de Relaciones Exteriores dando a conocer la imposibilidad de acudir a la invitación para tomar parte en la Exposición Bienal Hispanoamericana de Arte, no he cejado en mi propósito de que se revisase el acuerdo citado deiándolo sin efecto. /En entrevistas sostenidas con estos señores Ministros de Relaciones Exteriores y de Educación Nacional procuré hacer resaltar la suma conveniencia que para los artistas venezolanos representaba ef que sus obras figurasen entre las de los demás países hermanos, y, cuya ausencia, por otra parte, no dejaría de producir cierta extrañeza en aquéllos y contrariedad afectuosa en nosotros. Debo aclarar que el señor Ministro de Relaciones en todo momento se mostró propicio y entusiasta para la aceptación de nuestra invitación. Como resultado a las anteriores gestiones y a otras practicadas cerca de los señores Directores de Cultura, Díaz Sánchez, del Museo Nacional, Otero, etc., me es muy grato poder informar a V.E. que conforme a las últimas noticias el asunto ha sido puesto en marcha designándose el Jurado que habrá de seleccionar las obras, que, si bien no podrán llegar a ésa, sino entre el 10 y el 15 de septiembre, al menos, sea como fuere, no dejarán los artistas venezolanos de concurrir a la Bienal.» (Despacho número 438 de fecha de 3 de julio de 1951. AMAE, Leg. R-4.263, Exp. 22). 
Artes del Ministerio de Educación venezolano con la convocatoria a los artistas del país y señalando la fecha y lugar de entrega de las obras, a lo que rápidamente seguiría la designación de un jurado seleccionador ${ }^{14}$. Apenas si, desde la aparición del aviso, se dejaban diez días para que los artistas presentaran sus obras en el Museo de Bellas Artes, ritmo que haría al embajador insistir en que se le enviaran con urgencia las fichas que cada expositor debía rellenar para concursar en la Bienal ${ }^{15}$; aunque, no obstante, no tardaría en dar cuenta en un nuevo despacho, a la vez que de la satisfación por la concurrencia de Venezuela que le había expresado en carta particular el ministro de Relaciones Exteriores venezolano, de la aparición de unas tarjetas editadas por la Dirección Nacional del Museo de Bellas Artes de Caracas concediendo a los artistas venezolanos una prórroga hasta el 11 de agosto para la presentación de sus obras y fijando la fecha del 14 del mismo mes para la reunión del Jurado de Selección ${ }^{16}$. No era extraño, pues, que a partir de principios de agosto, la prensa española, comenzará también a hacer referencia con ufanía a la participación de Venezuela, que se esperaba abundante ${ }^{17}$.

14 Las condiciones de la convocatoria eran que cada artista podría enviar hasta un máximo de tres obras a cada una de las secciones de la Bienal, obras que serían seleccionadas por un Jurado venezolano de "personas de reconocida competencia en las Artes Plásticas» — que se designaría el día 11 de julio-y que debían ser remitidas al Museo de Bellas Artes de Caracas antes del 20 de julio. (Véase «Aviso Oficial. Estados Unidos de Venezuela. Ministerio de Educación. Dirección de Cultura y Bellas Artes», El Herando, Caracas, 10 de julio de 1951 -el Aviso quedaba fechado: Caracas, 3 de julio de 1951-; «Hoy se designan el Jurado que seleccionará las obras venezolanas al I Congreso Hispanoamericano de Arte», El Nacional, Caracas, 11 de julio de 1951.) Este Jurado, según despacho del embajador español, quedó compuesto por el director de Cultura y Bellas Artes, Ramón Díaz Sánchez; el director de la Escuela de Arquitectura, Willy Ossott; el director de la Escuela de Artes Plásticas, Bernardo Monsanto Cocking; el director del Museo de Bellas Artes, Carlos Otero; el asesor de Artes Plásticas, Gastón Diehl; el director de la Biblioteca Nacional, Enrique Planchart; un profesor de grabado de la Escuela de Artes Plásticas, Pedro Ángel González; un profesor de escultura de la Escuela de Artes Plásticas, Ernesto Margall, y un profesor de dibujo de la Escuela de Artes Plásticas, Luis Szepesi Moske (Despacho número 476 de fecha de 24 de julio de 1951. AMAE, Leg. R-4.263, Exp. 22).

${ }_{15}$ En el Telegrama número 105 expedido el 24 de julio de 1951 solicitaba al Ministro de Asuntos Exteriores español que se le enviaran con urgencia veinte fichas de expositor de cada una de las secciones de la Bienal. Calculaba el embajador -según Despacho número 476 de 24 de julio de 1951 que las obras podrían estar en Madrid en la primera quincena de septiembre. En el Telegrama número 136 de fecha de 21 de agosto de 1951 volvería a insistir ante el ministro en que diera las órdenes oportunas para que se le enviaran a la mayor brevedad las fichas solicitadas (AMAE, Leg. R-4.263, Exp. 22).

${ }_{16}$ Despacho número 494 de fecha de 6 de agosto de 1951, que adjunta el traslado de la carta particular de fecha de 6 de agosto de 1951 dirigida al embajador por el ministro venezolano y ejemplar de las tarjetas anunciando la prórroga y fecha de reunión del Jurado editadas por el Museo de Bellas Artes con fecha de 30 de julio de 1951 (AMAE, Leg. R-4.263, Exp. 22).

${ }_{17}$ En definitiva se habló, a la par que sobre la posible participación canadiense, de que había habido una extraordinaria acogida en Venezuela a la invitación oficial cursada por el ICH. EI Gobierno 


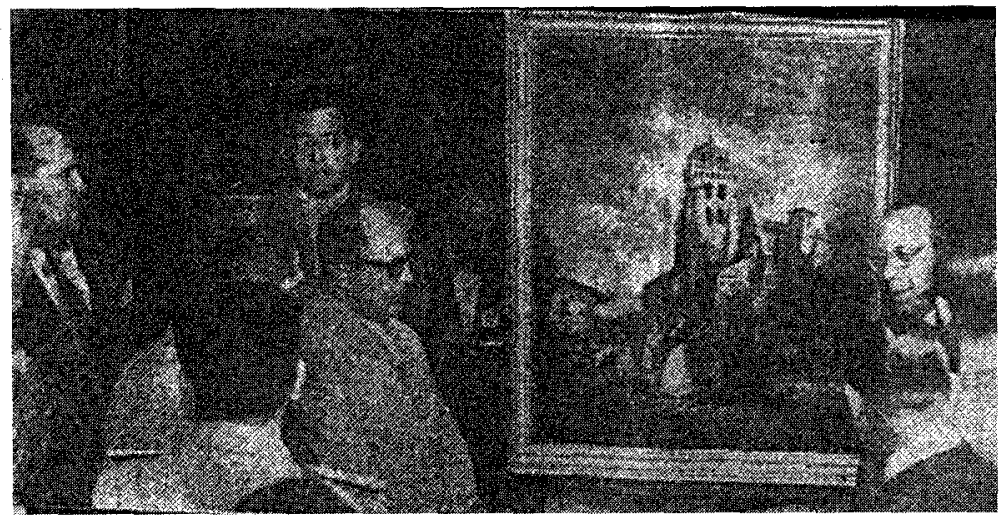

Fig. 1. Inauguración de la Exposición Antológica de la ll Bienal en Caracas (9 de enero de 1955).

Posteriormente, tras la selección de las obras presentadas por los artistas venezolanos, con ellas el Museo de Bellas Artes de Caracas organizó una exposición preparatoria que fue inaugurada en sus salas el 17 de agosto. «Estimo - decía el embajador español al informar sobre las obras y artistas de esta muestra- que podrán figurar con éxito al lado de las demás de otros países: se trata de 17 pinturas al óleo, 5 grabados, 5 dibujos, 2 esculturas presentadas por Antonio Alcántara, Marcos Castillo, Pedro Centeno, Pedro Angel González, Rafael Ramón González, Rafael Monasterios, Francisco Narváez, Carlos Otero, Gloria Pérez Guevara, César Prieto, Eduardo Schlageter, Santiago Poleto y Manuel Pérez. Figuran, además, fotografías y proyectos arquitectónicos de Jesús Higuera Jiménez y Carlos Raúl Villanueva" ${ }^{18}$. Incluso, subrayando el

venezolano, se decía, había hecho público un aviso oficial a través del Ministerio de Educación aceptando la invitación y anunciando las bases del concurso para remitir obras venezolanas por cuenta del Estado y habia nombrado un jurado calificador para la selección, siendo ya muchas las obras presentadas en la Dirección de Cultura para sił selección (véase «Canadienses y venezolanos participarán en la Bienal Hispanoamericana de Arte», El Alcázar, Madrid, 6 de agosto de 1951; «Canadá... Venezuela, en la Bienal», Arriba, Madrid, 7 de agosto de 1951; «Venezuela a la I Bienal Hispanoamericana de Arte», Pueblo, Madrid, 7 de agosto de 1951; «Venezuela y Canadá en la primera Bienal Hispanoamericana de Arte», La Vanguardia, Barcelona, 8 de agosto de 1951; "Canadá en la I Bienal Hispanoamericana de Arte. También participará Venezuela", Madrid, Madrid, 8 de agosto de 1951; "Información Hispanoamericana", Menorca, Mahón, 14 de septiembre de 1951).

18 Añadía el embajador la reseña de «la valiosa cooperación prestada al asunto por el señor Díaz Sánchez, director de Cultura, y por el señor Carlos Otero, director del Museo Nacional de Bellas Artes, que con verdadero interés acogieron las insistentes gestiones de esta Embajada para que se 


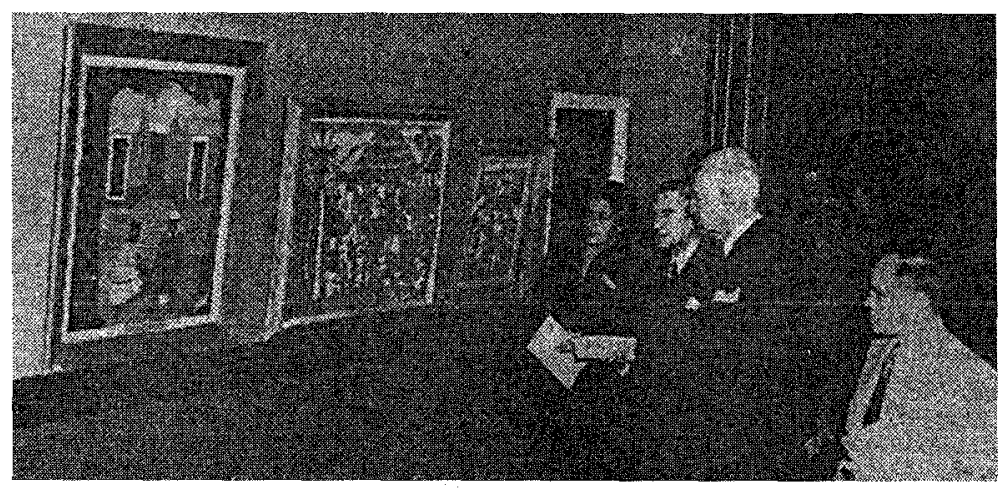

Fig. 2. Salas de la Exposición Antológica de la ll Bienal en Caracas (9-30 de enero de 1955).

apoyo y cooperación oficial de Venezuela, el mismo Gobierno de este país anunció a comienzos de septiembre la concesión de un premio de mil dólares con destino a la Bienal Hispanoamericana, lo que pronto fue difundido en la prensa ${ }^{19}$.

Para el primero de octubre, finalmente, junto a las fichas y documentación sobre los artistas, se mandaba a Madrid la selección hecha en Caracas ${ }^{20}$; aunque era la fecha tan tardía que, como también ocurriría

revisase la decisión tomada anteriormente y no quedasen ausentes los artistas venezolanos en la Bienal» (Despacho número 509 urgente de fecha de 18 de agosto de 1951). En posterior Despacho, a fines de agosto, Aguilar también envió una serie de fotografías de Venezuela, remitidas primeramente a la Embajada Española por el Ministro de Relaciones Exteriores venezolano con destino a la Bienal, ya que los organizadores de ésta habían pensado en celebrar paralelamente al certamen y en su marco una exposición del libro de arte del siglo $\mathrm{xx}$, de fotografías, etc. (Despacho número 527 urgente de fecha de 28 de agosto de 1951.) Ambos despachos en AMAE, Leg. R-4.263, Exp. 22.

19 La nota difundida decía: «El Ministro de Educación, J. Becerra, ha comunicado a la Embajada española, por medio del Departamento de Cultura, la concesión de un premio de 1.000 dólares para la Bienal Hispanoamericana de Arte que ha de tener lugar en Madrid el próximo mes de octubre y en la cual participan todos los países hispánicos" ("Mil dólares para la Bienal Hispanoamericana de Arte. Han sido donados por el Gobierno de Venezuela», Ya, Madrid, 2 de septiembre de 1951); noticia que incluso halló eco en la prensa mexicana (véase «Cables de España. Un premio de 1.000 dólares dará Venezuela», Excélsior, México D.F., 20 de septiembre de 1951). Este premio, dividido luego en dos de 20.000 pesetas, uno para escultura y otro para pintura, correspondió a los españoles José Planes y Juan Antonio Morales.

zo Véase Despacho número 594, de fecha 1 de octubre de 1951 del encargado de negocios a.i. de España en Caracas, A. de Maldonado, y telegrama del mismo número 71 expedido el 13 de octubre de 1951 (AMAE, Leg. R-4.263, Exp. 23). 
con los envíos de otros países, no lograría estar a tiempo para la inauguración oficial del Día de la Hispanidad. La mayor parte de esta selección, como ocurrió también con parte de la aportación de Argentina, Colombia, Cuba, Chile y Brasil, hubo de ser instalada en las salas del Museo Arqueológico que se acondicionaron para dar cabida a estos envíos tardíos, salas que fueron inauguradas el 15 de noviembre con asistencia de los representantes diplomáticos de estos países. Los artistas venezolanos que finalmente exhibía la Bienal madrileña eran, pues, más o menos, los mismos que relacionaba el embajador español al reseñar en agosto la exposición de Caracas, es decir, unos quince artistas ${ }^{21}$; selección sobre la que la crítica española puso de relieve que se trataba, casi en su totalidad, de paisajistas, destacando los paisajes puntillistas de César Prieto, como hacían, por ejemplo, Antonio Oliver, Luis Figuerola Ferretti y Alberto del Castillo, o distinguiendo entre «pasajistas de la forma impresionista (Pérez Guevara, Carlos Otero, Alcántara) y los más contructivistas (Ramos González, Prieto y Monasterio)», como hacía Luis Felipe Vivanco ${ }^{22}$.

A pesar, pues, de los titubeos del Gobierno venezolano, cuya colaboración, con todo, fue agradecida por el español ${ }^{23}$, y del retraso con que

${ }^{21}$ En el catálogo general de la Bienal no figura ninguna obra de Pedro Centeno, sin embargo, además de los pintores (A. Alcántara -2 óleos-, M. Castillo -2 óleos y 1 dibujo-, P. A González - 1 óleo y 2 grabados-, R. Ramón González - 3 óleos-, R. Monasterios -1 óleo-, F. Narváez - 1 óleo-, C. Otero -2 óleos y 1 dibujo-, G. Pérez Guevara - 1 óleo, 1 dibujo y 3 grabados-, C. Prieto -3 óleos-, E. Schalegeter -2 óleos-) y los escultores (S. Poletto Lamberti y $M$. Pérez, con una pieza cada uno) referidos por el embajador en el despacho aludido, también aparecen los pintores $C$. Sosa -2 óleos y 2 dibuios-y María Lionza - 1 óleo-. En lo referente a los arquitectos sólo figuran las «Realizaciones urbanas en la Universidad de Caracas» de Carlos Raúl Villanueva (asiento número 1.747), sin que aparezca nada de Jesús Higuera Jiménez (véase el catálogo general / $B$ ienal Hispanoamericana de Arte, Madrid, Gráficas Valera, S. A. [(1951), págs. 132-134, 165-166, 184, 186 y 202].

${ }_{22}$ A. Oliver: «Crítica de la Primera Exposición Bienal Hispanoamericana de Arte», Cortijos y Rascacielos, números 67-68, Madrid, 1951, pág. XX; L. FIGUerol.F-FARRETTl: «Primera Bienal Hispanoamericana. Pintura hispanoamericana, de Portugal, Estados Unidos y Filipinas», Arriba, Madrid, 6 de enero de 1952 (también destacaba la inspiración impresionista de las obras de Pérez Guevara y Alcántara); A. DEL CASTILLO: «La pintura americana, filipina y portuguesa en la Bienal», Diario de Barcelona, Barcelona, 13 de enero de 1952; L. F. Vivanco: Primera Bienal Hispanoamericana de Arte, Madrid, Afrodisio Aguado, 1952, págs. 60-61.

23 Cuando acaba la I Bienal, el mismo dirrector del ICH envió al nuevo embajador de España en Caracas, Gonzalo de Ojeda, un Saluda a su agredecimiento y acompañado de un catálogo del certamen para que lo hiciera llegar al presidente de la República venezolana, Fernando Suárez Flamerich. El embajador aconsejó entonces al Ministro español de Asuntos Exteriores (Despacho número 125, de fecha de 29 de febrero de 1952) que «teniendo en cuenta el interés del Catálogo y la persona a que va dedicado» fuera «encuadernado debidamente y ofrecido en carta firmada por V.E." al Ministro de Relaciones Exteriores venezolano rogándole su entrega a dicho presidente a la vez que ofreciendo a este ministro un obsequio análogo. Y poco tiempo después así lo hacía el ministro español que, por conducto del citado embajador, enviaba los catálogos y una carta 
llegara el envío, todo parecía que había ido bien en Venezuela, sin embargo, la cuestión de participar en un certamen convocado por el régimen del general Franco no había estado exenta de problemas y prejuicios entre los artistas y el mundo intelectual caraqueño.

Es decir, la Bienal Hispanoamericana, desde los primeros momentos de su organización, halló la repulsa de numerosos artistas americanos y españoles exiliados, debido especialmente al régimen político invitante, sobre el que argüían que no tenía autoridad ni estatura moral para intervenir en materia cultural convocando a un certamen artístico de esas características. Su actitud de aversión y repulsa del certamen, se expresó así a través de inhibiciones, ausencias, firmas de manifiestos y llamados, conferencias, declaraciones y cartas abiertas dirigidas a los diarios, etc., aunque, sin duda, la forma de condena halló su cauce más significativo en la organización de exposiciones de réplica a la celebración de este certamen o «contrabienales», como se las llamó. Ello arrancaba de la propuesta de celebrarlas que hizo un manifiesto firmado por Pablo Picasso y otros artistas e intelectuales españoles exiliados en París.

Precisamente, este manifiesto vio la luz a comienzos de septiembre de 1951 publicado en el diario El Nacional de Caracas, encabezando sus firmas Pablo Picasso y, por el Comité Organizador, el escultor Baltasar Lobo, el escritor Arturo Serrano Plaja y el poeta Antonio Aparicio; aparición a la que seguramente no fue ajena la celebración en agosto en el Museo de Bellas Artes de Caracas -el mismo que celebraba la exposición preparatoria de la Bienal- de una exposición del pintor venezolano Gabriel Bracho, uno de los principales y más destacados organizadores de la futura «contrabienal» caraqueña, asi como la celebración por las mismas fechas y en idéntico Museo de una muestra de los artistas españoles de la Escuela de París, en la que estuvieron el escultor Baltasar Lobo (firmante por el Comité Organizador - recordemos- del manifiesto y en algún modo ligado a Caracas, donde le llamara el arquitecto Carlos Raúl Villanueva para colaborar en el proyecto de la Ciudad Universitaria) y algunos de los más destacados pintores del grupo parisino (Oscar

(fechada el 20 de marzo de 1952) a su homónimo venezolano, Gómez Ruiz, rogándole se reservara uno e hiciera llegar el otro al presidente, a la par que aprovechaba «esta oportunidad para reiterarle, en nombre de este Gobierno y de los organizadores de la Bienal Hispanoamericana de Arte, la gratitud más sincera por la colaboración que en todo momento hemos encontrado por parte de esa nación para el mejor éxito de esta exposición de arte», mostrándose el ministro venezolano, pronto visitado por el embajador español, «sumamente complacido y muy interesado en el resultado de la Exposición aludida» (Despacho número 50 de fecha de 3 de abril de 1952). Ambos despachos y copia de la carta en AMAE, Leg. R-4.263, Exp. 23. 
Domínguez, Joaquín Peinado, Hernando Viñes, Pedro Flores, etc) ${ }^{24}$. Aunque, en cualquier caso, enseguida otras publicaciones de la capital se hicieron eco del manifiesto, como el semanario caraqueño Morrocoy Azul, publicación precisamente a través de la cual tuvo noticia el Ministerio de Asuntos Exteriores español de la existencia de la llamada y que comentaba el proyecto de la Bienal en el sentido de que no era sino una manifestación política y una maniobra del falangismo para fortalecerse en el poder «en el momento más agudo de su bancarrota», esperándose «que los artistas americanos no caigan en esa red y menos los venezolanos, que por antifranquismo, no acudirán a la repetida Exposición», añadiendo, por último, que el régimen español no podía «patrocinar el arte después de los «asesinatos» cometidos con literatos, poetas, pintores, etc.» ${ }^{25}$.

La influencia de este llamamiento que, además de condenar y oponerse a la Bienal de Madrid, advertía a los artistas americanos «del verdadero contenido de tal invitación" y proponía la celebración de exposiciones paralelas de réplica ${ }^{26}$, fue manifiesta, pese a que lo tardío de su aparición

24 Sobre las exposiciones de Gabriel Braho y del grupo de artistas españoles de la Escuela de París, véase Gastón DiEHL: "Medio año en la vida artística de Caracas", Artes, número 1, Caracas, abril-junio, 1952, págs. 45-46.

25 Nota ITE-4.458-11-175.06 informativa de la prensa venezolana, del Servicio de Información de Temas Españoles de la Oficina de Información Diplomática del Ministerio de AA.EE., que da cuenta sobre la aparición de un artículo dedicado al manifiesto (publicado el 8 de septiembre de 1951 en el semanario caraqueño Morrocoy Azul) y que com enta la Bienal en el sentido expuesto (AMAE, Leg. R-4.263, Exp. 23). Con todo, en España, el manifiesto no fue publicado de forma íntegra hasta noviembre ( Este es el manifiesto de Picasso. Propone una contrabienal... en París", Correo Literario, números 34-35. Madrid, 1 de noviembre de 1951, págs. 1 y 8), aunque se sabía públicamente de su existencia desde que un mes antes el crítico Manuel Sánchez Camargo diera la noticia al replicarlo ("Picasso y la Bienal Hispanoamericana», Arriba, Madrid, 1 de octubre de 1951). De todos modos, el manifiesto fue conocido tardiamente en la mayor parte de los países y así, por ejemplo, en México, donde dio origen a otra importante «contrabienal», sólo comenzó a conocerse hacia mediados de octubre. Por entonces, P. Fernández Márquez lo comentaba largamente ("Panorama de las artes plásticas. Carta de Picasso a los Artistas de Habla Española», EI Nacicnal, «Suplemento Dominical», número 237, México D.F., 14 de octubre de 1951, pág. 7), al igual que Juan Rejano insistía en la invitación de Picasso a celebrar exposiciones paralelas a la madrileña («Cuadernillo de señales. La Bienal de los chacales», El Nacional, México D.F., 14 de octubre de 1951, págs. 3 y 7). También en ia misma fecha Rosa Castro transcribía y resumía algunos párrafos («Genio y figuras. Intervención de Picasso. Magna Exposición Anual», Excélsior, México D.F., 14 de octubre de 1951, pág. 7c) y, pocos dias después, El Popular lo publicaba íntegramente ( CCarta de Picasso y otros artistas y escritores españoles a los artistas de América Latina”, El Popular, México D.F., 21 de octubre de 1951, pág. 6).

26 El manifiesto, aparte de expresar su repulsa hacia el proyecto de la Bienal, «fanfarronada imperial» con la que se pretendía, decían, "contrapesar idealmente la espantosa miseria que en la actualidad sufre el pueblo español» y que portaba las evidentes intenciones «de atraer a los artistas de habla española y de darse pretexto para acercarse culturalmente a los Estados Unidos", intentaba «advertir a los artistas de los diferentes paises de América acerca del verdadero conte- 
y las dificultades de difusión le restaran trascendencia y eficacia. Destacó singularmente, entre las actuaciones de réplica a la Bienal a que dio lugar su conocimiento entre los artistas americanos, las "contrabienales» celebradas en Caracas, París y México ${ }^{27}$, siendo la venezolana, tras la buena acogida dispensada en Caracas a la aparición del manifiesto de Picasso,

nido de tal invitación, el cual no es otro que el de una invitación a colaborar con el franquismo..., acudir a España, aceptar tal invitación oficial es asumir la responsabilidad moral de colaborar con un régimen que la opinión mundial ha condenado y condena» y, a la par, buscaba que hubiera «una iniciativa española, precisamente española, que se proponga subrayar la hondísima significac ión que para España y América principalmente, tiene la fecha del 12 de octubre»; para lo que proponía tanto «celebrar en París una exposición de artes plásticas, de carácter hispanoamericano exclusivamente, en la que podrían participar el grupo de pintores y escultores españoles residentes en París más los artistas americanos que se encuentren en esta capital», como "celebrar exposiciones análogas en algunas capitales de América (Buenos Aires, Méjico, Río de Janeiro, por ejemplo), contanto con los artistas de los países respectivos a dichas capitales, más los españoles refugiados en los mismos», exposiciones, que el manifiesto llamaba "centrales» y que debian subrayar, tanto en París como en América, su carácter afirmativo" mediante otras manifestaciones artísticas (conciertos, lecturas, exposiciones de libros, etc.)». Al mismo tiempo, invitaban a los artistas americanos a enviar sus obras a algunas de las diversas exposiciones «centrales» $y$, «cuando por diferentes razones, en alguno de dichos países no fuera posible organizar tal envio, realizar exposiciones locales, pero de acuerdo y simultáneas con aquellas que hemos llamado centrales»y, finalmente, para poder realizar tales proyectos, proponian cuidar siempre de «subrayar el carácter español y libre de tal iniciativa; recabar la colaboración de personalidades, tanto españolas como americanas, de autoridad moral no sólo capaz de jerarquizar nuestro propósito, sino también de canalizar la oposición de otros artistas y escritores americanos».

${ }^{27}$. Ninguna de las tres, sin embargo, se celebró simultáneamente como proponía el escrito y sólo la de Caracas coincidió con la fiesta del 12 de octubre. Entre esta fecha y la del 12 de abril de 1952, en la que se cerraba la muestra mexicana, se inscribió la celebración de este tipo de exposiciones, insistiendo cada una de las señaladas en unos aspectos del manifiesto que la harian diferente respecto a las demás, abarcando desde la faceta más bien localista de la caraqueña a la pretensión de internacionalidad y centralización de la parisina. Es decir, si la actividad de Caracas, la que más al pie de la letra siguió al manifiesto, hay que considerarla, principalmente, como un acto cultural y reivindicativo de «La España democrática», de sabor - pese a todo- bastante local y con participación casi única de venezolanos $-\mathrm{y}$ no todos artistas plásticos-; en otro extremo, la muestra de París, tan difícil de organizar y finalmente inaugurada en la Galerie Henri Tronche de París el 30 de noviembre, aunque con apenas una obra por cada artista, en su ensanchada vocación hispana -y menguados resultados- exhibió creaciones de pintores y escultores españoles exiliados y de doce países americanos, destacando entre los cuarenta artistas representados Picasso, Antoni Clavé, Oscar Domínguez, Apel les Fenosa, Baltasar Lobo...; Diego Rivera, Alfaro Siqueiros, Chavez Morado, Carlos Mérida, Wifredo Lam, Carmelo Arden-Quin, Nemesio Antunez, Alejandro Obregón..., mientras que en la capital mexicana, aunque con gran retraso y únicamente convocando a los pintores mexicanos y españoles transterrados, se inauguró el 12 de febrero en el Pabellón de la Flor del Bosque de Chapultepec la exposición más comprometida, combativa y concurrida por un mayor número de obras y axtistas, entre quienes podriamos resaltar a Rodríguez Luna, José Renau, Vicente Rojo, Moreno Villa, Elvira Gascón, Fernández Balbuena, Miguel Prieto, Camps Ribera, Giménez Botey...; Diego Rivera, Siqueiros, Chavez Morado, Rufino Tamayo, María Izquierdo, Leopoldo Méndez, Xavier Guerrero, Mexiac, Ignacio Aguirre, O’Higgins, Rodríguez Lozano, Olga Costa, Raưl Anguiano, Germán Cueto, Angelina Beloff, Guillermo Meza, Guerrero Galván, Orozco Romero... 
la actuación que más se atuvo al carácter de "actividad positiva» solicitado por el escrito para celebrar la fecha del 12 de octubre.

Es decir, lo que en Caracas se celebró fue una "Semana de la Cultura", que, organizada por los artistas a instancias tal manifiesto y como adhesión a su postura, se desarrolló entre el 12 y el 20 de octubre. El principal impulsor y organizador de esta Semana fue el Taller Libre de Arte, que esperaba «reivindicar así para el 12 de octubre aquel significado de acontecimiento creador de vínculos de fusión histórica y espiritual entre los pueblos americanos y el pueblo español, que una acartonada tradición académica quiso siempre ocultarlos en beneficio de un criterio racista tan anti-español como anti-americano». Invitó este Taller a destacados escritores, pintores, músicos y, en general, artistas e intelectuales venezolanos a participar en una serie de actos programados con tal motivo a lo largo de la semana, "a la que todos los pensadores venezolanos supieron responder en forma efectiva, inspirados en su sentimiento por la hispanidad, y a la vez invocando el santo nombre de la España democrática, a la que pertenece Picasso, Alberti y muchos otros que se han hecho del mundo ciudadanos universales, en la angustiada búsqueda de un medio mejor». Colaboró también el Ateneo de Caracas, donde el pintor Gabriel Bracho leyó el mensaje de salutación y contestación del Taller Libre de Arte al llamamiento parisino y, en cuyas salas, se abrió la exposición «contrabienal» de pintores y escultores venezolanos, muestra que, además, se complementó con otra exposición, aunque esta de caricaturas, celebrada en las salas del mismo Taller Libre de Arte. Por otro lado, se completaron estos actos, donde los artistas plásticos tuvieron un especial protagonismo, con la celebración de otras actuaciones también de sentido cultural, como las palabras inaugurales de la semana pronunciadas por el poeta Juan Liscano y la conferencia sobre el sentido de la hispanidad del historiador Mario Briceño Iragorry en el Ateneo de Caracas, el concierto de Antonio Esteves y el Orfeón Universitario en el mismo lugar, los recitales de poesía de Aquiles Nazoa en el Instituto Escuela y otras varias actuaciones de figuras del mundo de la cultura caraqueña ${ }^{28}$.

${ }^{28}$ Además de los citados, también protagonizaron actuaciones a lo largo de la semana Mariano Picón Salas, Luz Machado de Arnao, Ida Gramcko, Manuel Trujillo, Lucila Velázquez, Ernesto Luis Rodríguez, Alarico Gómez, Carlos Augusto León, J. D. Armas Chitty, Eliseo Jiménez Sierra, Francisco Salazar Martínez, Balbino Blanco Sánchez, Agustín Rodríguez, Antonio Nieves, Juan F. Palacios, Heriberto Colmenares, Candelario Prieto, Cruz Aviła, César Henríquez, Federico Reina. (Véase «La Semana de la Cultura», Elite, número 1.359, Caracas, 20 de octubre de 1951, pág. 17.) 
Caracas: Un intento frustrado de continuidad de las bienales hispanoamericanas...

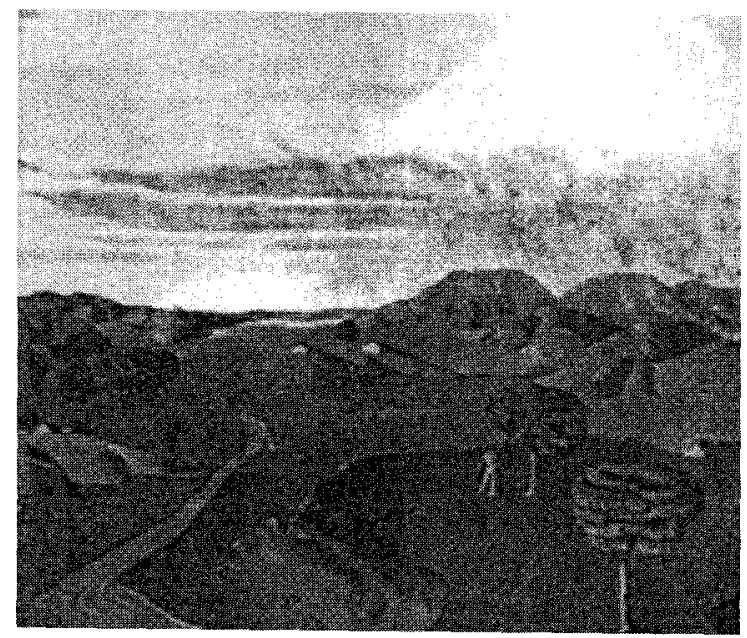

Fig. 3. PEDRo León CASTRo: Armonia, óleo (II Bienal y Antológica de Caracas).

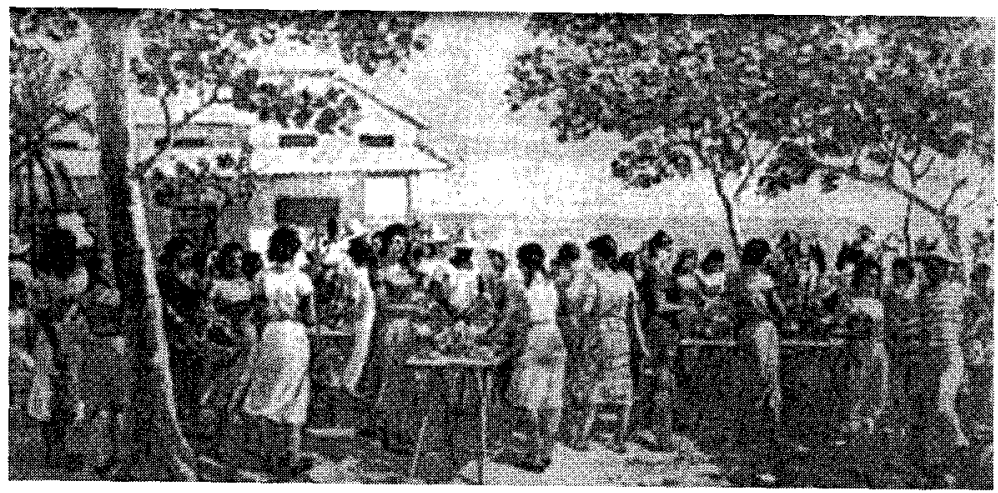

Fig. 4. Carlos Otero: Día de mercado, óleo (II Bienal y Antológica de Caracas).

Y, a la par que esta actividad en Caracas, no está de más recordar, en el mismo sentido, que en París -el otro polo de desarrollo del arte venezolano- la participación de los artistas venezolanos en la exposición "contrabienal» allí organizada fue la más numerosa tras la de artistas españoles exiliados, es decir, a la pequeña muestra parisina concurrieron los artistas venezolanos Armando Barrios, Omar Carreño, Héctor Poleo, 
Adela Rico de Poleo y Pedro Rojas, todos ellos residentes en esos momentos en la capital francesa ${ }^{29}$.

La ambigüedad, pues, estuvo siempre presente en la mirada de Venezuela hacia la Bienal Hispanoamericana y la doble actitud y contradiciones del Gobierno, que tanto comunicaba su asistencia oficial a la Bienal madrileña como se desdecía o que igual celebraba oficialmente en concordancia con España el «Día de la Raza» ${ }^{30}$ como no ponía reparos a que se organizara una semana cultural «invocando el santo nombre de la España democrática», aparecería nuevamente en la siguiente edición de la Bienal Hispanoamericana.

Esta II Bienal, al señalar los Estatutos del certamen la posibilidad de realización alternativa de las ediciones en España y otros paises ${ }^{31}$, fue celebrada en la capital cubana, donde el gobierno del general Fulgencio Batista se aprestó a copatrocinarla para ser incluida como acto destacado de la conmemoración en 1953 del Centenario Martiniano ${ }^{32}$; aunque diversas

29 Barrios expuso el gouache "Composición», Carreño el óleo «Composición», Guevara "Relief coleur trois formes", Poleo el gouache "Figura», Rico la pieza cerámica "La mujer del gallo" y Rojas el óleo "Isabel Vicente», véase "Catalogue des oeuvres exposées" en Exposition Hispano-Americana. Galerie Henri Tronche, 30 novembre-22 decémbre 1951, París, Mourlot Frères, 29 de noviembre de 1951, págs. 17-22; sobre el paso por París: José Gómez Sicre: "Pintores venezolanos en París", El Farol, número 134, Caracas, págs. 10-13.

so Véase "Día de la Raza", Elite, número 1.359, Caracas, 20 de octubre de 1951, pág. 16.

${ }^{31}$ Los Estatutos definitivos de la | Bienal señalaban (art. 49) que la exposición se celebraría «en Madrid cada dos años», reservándose «el año intermedio para la realización de la misma en el país hispanoamericano que se proponga organizarla" [Exposición Bienal Hispanoamericana de Arte. Estatutos, Madrid, Gráficas Valera, s./f. (1950); también reproducidos en el catálogo general de I Bienal, op. cit., págs. XXVII-XXXII], pero tras su clausura se modificaron en el sentido de que fuera organizada una edición en España (sin la exclusividad de Madrid) y la sucesiva en el país iberoamericano que quisiera patrocinarla, regresando la siguiente edición a la península y así sucesivamente (véase el mismo artículo en «Estatutos de la II Bienal», reproducidos en II Bienal Hispanoamericana del Arte. Catálogo General. Palacio de Bellas Artes. La Habana, 1954, La Habana, Impresora Mundial, 1954).

${ }_{32}$ Recordemos que la celebración de la II Bienal en Cuba fue ya anunciada - al tiempo que la III Bienal en Barcelona- por el director del $\mathrm{ICH}$ al clausurar la antología de la I Bienal en la Ciudad Condal (véase "La II Bienal de Arte Hispanoamericano se celebrará en la Ciudad Condal», Informaciones, Madrid, 25 de abril de 1952; «La segunda Bienal Hispanoamericana», Madrid, Madrid, 25 de abril de 1952; "Homenaje a unos artistas", La Prensa, Barcelona, 24 de abril de 1952; "La III Bienal de Arte se celebrará en Barcelona», El Correo Catalán, Barcelona, 26 de abril de 1952; "La II Bienal en Cuba», Solidaridad Nacional, Barcelona, 1 de mayo de 1952). Fue, por otro lado, muy importante la sugerencia y gestión de la Embajada de España en Cuba para lievar allí la Bienal, así como el apoyo de su titular, Juan Pablo Lojendio, marqués de Vellisca, quien habia sido anterior director general de Relaciones Culturales (cargo que asumió en febrero de 1951 reemplazando a Carlos Cañal, marqués de Saavedra, quien le reemplazaba como ministro plenipotenciario de España en Uruguay), precisamente durante la organización y celebración de la ! Bienal, de la que fue vicepresidente y formó parte de juntas de organización, jurados de selección y calificación, reuniones, etc. -aunque en realidad él mismo tomó parte activa, 
razones que enseguida veremos hicieron que no pudiera ser inaugurada hasta el 18 de mayo de 1954, permaneciendo abierta hasta su clausura el 10 de septiembre del mismo año, a partir de donde continuaría con una serie de exposiciones antológicas en Centro y Sudamérica, entre las que especiamente nos detendremos en la que se llevó a Caracas ${ }^{33}$.

Mas incidiendo en algunas de las más destacadas visicitudes de esta Bienal habanera, tan mal conocida en España, digamos que, en principio, aparte de pensarse como evento artístico que clausurara las celebraciones del Centenario del libertador antillano e inaugurara a la par el PalacioMuseo Nacional de Bellas Artes que se edificaba en La Habana, los retrasos en la construcción de este edificio, así como la oposición de numerosos artistas e intelectuales cubanos a la celebración de este «acto franquista» entre los demás dedicados en 1953 a la memoria de José Martí, hizo que el certamen retrasara su fecha de inauguración varias veces, perdiendo su ritmo bianual.

si bien hizo que la Dirección General de Relaciones Culturales estuviera siempre presente en todos estos procesos- Corno embajador de España en Cuba (en junio de 1952 Luis García de Llera sustituía a Lojendio como director general de Relaciones Culturales), el marqués de Vellisca tuvo un papel muy activo y directo para conseguir organizar la II Bienal Hispanoamericana en este país caribeño, Bienal que como él mismo rememoraba en un despacho con el ministro de Asuntos Exteriores español, se habia incluido por sugerencia de esta Embajada en los actos conmemorativos del Centenario de Martí, porque su Junta Organizadora era «la única entidad con medios económicos suficientes para hacer frente a la realización de dicha Exposición» (Despacho número 34 fechado: La Habana, 19 de marzo de 1954. AMAE, Leg. R-4.262, Exp. 11, copia en Archivo General de la Administración -en adelante citado AGA-, Sección Asuntos Exteriores, Caja 5.379).

${ }^{3}$ En general, esta II Bienal contó con unos estatutos, una convocatoria, un sistema de selecci pon y, en definitiva, una organización que, aparte de las peculiaridades que prestaban las dobles comisiones, juntas, jurados, etc., cubanos y españoles y las características y medios del nuevo país, fueron muy parecidos a los de la Bienal de Madrid y luego de Barcelona. En cuanto a la línea artística que se dedujo de la selección y el fallo de su jurado, se continuó la orientación iniciada en Madrid, siendo ahora el ecléctico momento en que recayeron los premios en artistas españoles como Ortega Muñoz, Sunyer, Pedro Flores, Manuel Humbert, Menchu Ga!, Amadeo Gabino, Carlos Pascual de Lara, Prieto Nespereira, José Clará, José Planes, Vázquez Molezún, Lloréns Artigas, Antoni Cumella, etc., y artistas americanos como Mirta Cerra, M. Teresa de la Campa, Héctor Poleo, Glyn Jones, Carlos Sobrino, Carmelo González, T. Ramos, A. Rodríguez Pichardo, E. Barañano, A. Carreño, etc. Por otro lado, extendiendo el aspecto propagandístico —o promocional, como se justificó - del arte español, la Bienal, tras la clausura en La Habana, fue llevada de la mano de Leopoldo Panero, Luis González Robles y Pedro Roselló, seleccionada y en forma de exposiciones antológicas, a varios países americanos: a la República Dominicana (antológica celebrada en Ciudad Trujillo - Santo Domingo- del 24 de octubre al 14 de noviembre de 1954), a Venezuela (celebrada en Caracas del 9 al 30 de enero de 1955), a Colombia, donde recorrió sucesivamente las ciudades de Bucaramanga, Medellín, Cali, Tunja y Bogotá, y una serie de prolongaciones a Panamá, Sao Paulo, Quito, Lima y Santiago de Chile. 


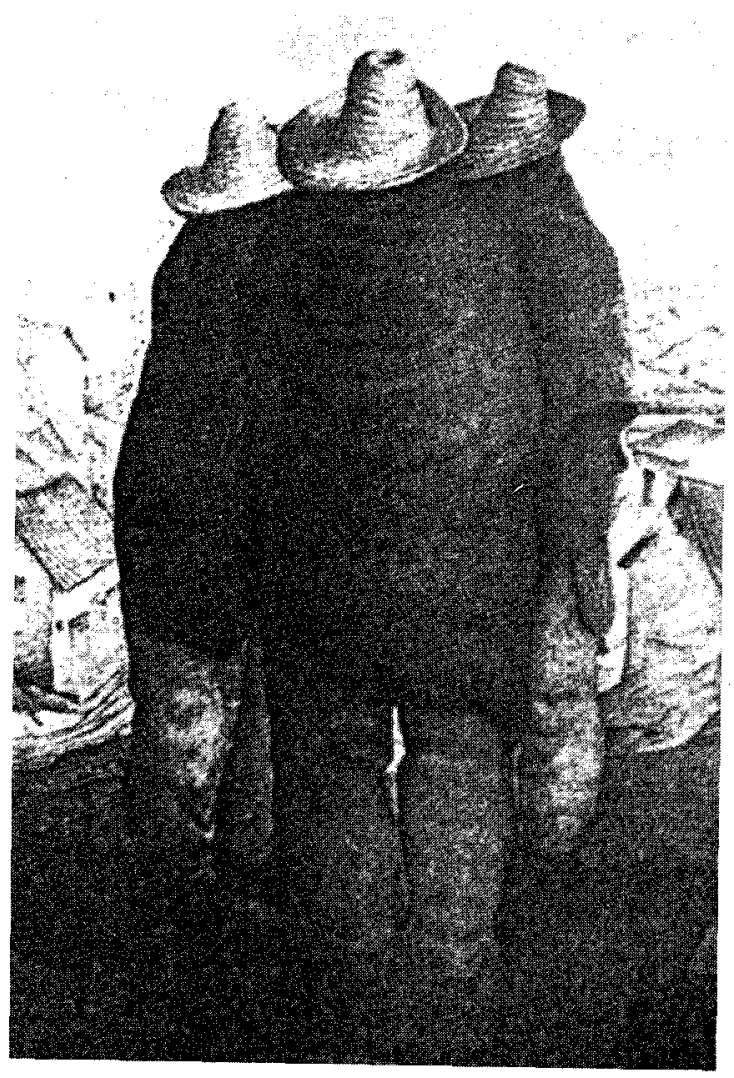

Fig. 5. HÉCtOR POLEO: Los tres comisarios, óleo (II Bienal y Antológica de Caracas).

La oposición a que se realizara en Cuba esta II Bienal, empezó a ser muy clara en octubre de 1953, cuando los artistas cubanos, encabezados por el pintor Mario Carreño, comenzaron a hacer oír su repudio e intención de no asistir al certamen. Momento también en que el director del $\mathrm{ICH}$ y presidente de la Bienal, Alfredo Sánchez Bella, viajaba a la Isla intentado agilizar la organización y celebración de la muestra ${ }^{34}$. Sin embargo, el rechazo fue acrecentánciose con la hostilidad mostrada por la

\footnotetext{
${ }^{34}$ Véase: Luis Dulzaides Noda: «El caso de la Bienal Hispana», Pueblo, La Habana, 28 de octubre de 1953; F. Jerez Veguero: «La Hispanidad en acción», Tiempo, La Habana, 29 de octubre de 1953; Mr. Bitter: “Póngale el cuño», Tiempo, La Habana, 29 de octubre de 1953.
} 


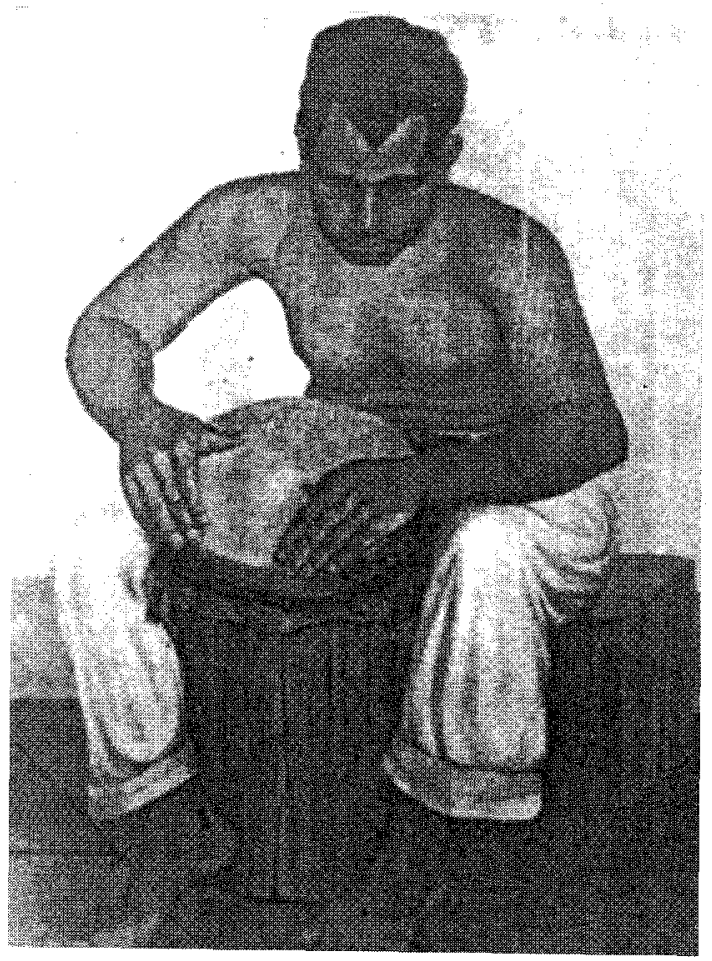

Fig. 6. CÉSAR RENGIFO: Estudio, óleo (II Bienal y Antológica de Caracas).

revista habanera Bohemia y su campaña de descrédito del certamen ${ }^{35}$ y siguió en aumento a medida que se acercaba el día 28 de enero, natalicio

35 Insistía ésta en que el "origen de la Bienal Franquista» estaba en el falangismo y un Instituto de Cultura Hispánica heredero de los afanes imperialistas del Consejo de la Hispanidad, que ahora buscaban celebrar su segunda edición en La Habana acaparando fondos de la Comisión de Actos y Ediciones del Centenario de Martí ("Origen de la Bienal Franquista", Bohemia, número 45, La Habana, 8 de noviembre de 1953). También Jerónimo Lamar insistió desde la misma publicación en la financiación del certamen por la citada Comisión para cerrar "con broche de oro" los actos del Centenario, pese a que los principios que defendió Marti estaban en pugna con los que regían "el régimen totalitario que padece España», lo que habia hecho que los artistas más destacados de Cuba hubieran decidido no concurrir a «ese evento de indudable proyección de publicidad franquista». Y terminaba aportando la opinión de varias personalidades entrevistas -es decir, los artistas Mario Carreño, Amelia Peláez, Alfredo Lozano, Cundo Bermúdez, Jorge Arche y Guido Llinás (que hablaba en nombre del "Grupo Los Once»), la crítica Gladys Lauderman y el estudioso martiniano Gonzalo de Quesada-, quienes coincidian en 
de José Martí y fecha programada para inaugurar la II Bienal Hispanoamericana dando con ello por concluido oficialmente el año de actos de celebración del Centenario.

Así, el aumento de los problemas con los artistas e intelectuales que les apoyaban, el retraso en la construcción del edificio, los dificultades políticas internas, etc., hicieron al Instituto de Cultura Hispánica pensar en aquellos momentos en la posiblilidad de cambiar de planes y organizar esta II Bienal en Caracas, coincidiendo con la inauguración de la $X$ Conferencia Interamericana. De esta suerte, el director del $\mathrm{ICH}$, en el curso de su gira por los países americanos intentando resolver el tema de su concurrencia a la II Bienal, escribía al director de Relaciones Culturales del Ministerio de Educación cubano, López Isa, comunicándole que era ya segura la participación de varios países por los que había pasado (Santo Domingo, Haití, Venezuela, Panamá, Costa Rica, El Salvador, Colombia, Ecuador, Perú, Chile y Bolivia, además de Brasil que ya había hecho el envío y Argentina donde realizaría las gestiones la semana siguiente), así como que el material español estaba en Barcelona listo para embarcar y abrir la Bienal el 28 de enero; pero preguntaba a que se debía el "extremado y total silencio" cubano y cuales eran los problemas en torno al certamen, añadiendo:

«Te ruego por favor claridad y rapidez en la información que solicito para proceder en consecuencia. Nosotros hemos hipotecado nuestro nombre en todos los países, los envíos están en camino y no pueden quedar decepcionados. Decidme, pues, si quedaron definitivamente solucionadas todas las dificultades, cuál es vuestro punto de vista sobre todas las cuestiones y en qué forma pensáis inaugurar el día 28.

De existir inconvenientes insuperables también te ruego me los comuniques sin tardanza; todavía habría tiempo de rectificar sobre la marcha y cumplir lo promeido en otro lugar. Precisamente la circunstancia de la inauguración en Caracas a comienzos de marzo de la $X$ Conferencia Panamericana nos daría ocasión para que, en caso de que ahora vosotros tuviérais dificultades, desplazáramos rápidamente todo el material a Caracas, a fin de abrirla coincidiendo con la inauguración de la Panamericana o acaso 15 días antes. Ésta podría ser una solución in extremis. La muestra una vez que visitara Venezuela y acaso algún otro país podría ser presentada en La Habana, no ya como primicia, naturalmente,

considerar a la Bienal como un «acto antimartiniano» y proponían que el Estado cubano convocara una «Exposición Martiniana Internacional del Arte» de nuevo cuño y sin interferencia extranjera ( $J$. Lamar: «De acto antimartiniano a la Bienal de Arte Hispanoamericano», Bohemia, número 47, 22 de noviembre de 1953, págs. 64-65 y 85). 
pero sí como expresión de lo que en fecha oportuna podría haberse hecho» ${ }^{36}$.

Sin embargo, Caracas siguió su propio ritmo sobre la preparación de la muestra que acompañara a esta X Conferencia Interamericana a celebrar en marzo en el Aula Magna de la Ciudad Universitaria ${ }^{37}$, quedando el tema únicamente en unas primeros contactos sobre el hecho de llevar la Bienal Hispanoamericana a Venezuela -que luego se recogerán en el proyecto de celebrar la IV Bienal- y en un precedente de la intención de la Bienal Hispanoamericana de asociarse con las Conferencias de la OEA, que volvió a resurgir con el proyecto de celebrar la IV Bienal en Quito cuando hubo de renunciarse al de Caracas. La organización de la II Bienal, pues, siguió adelante en Cuba, pese a la oposición de los artistas e intelectuales cubanos más dinámicos, quienes se habian unido lanzando manifiestos y editando boletines de protesta en forma de cartel. Principalmente, como exponían en un manifiesto firmado a finales de octubre de 1953, protestaban por la celebración de esta Bienal dentro de los festejos del Centenario Martiniano, por la participación del gobierno cubano en la financiación del certamen y porque la organización de la muestra correspondiera a un gobierno extranjero; proponiendo, a su vez, la celebración de una «Expcsición Martiniana Internacional de Arte» ${ }^{38}$. Además

36 AÑAdía SÁNCHEZ BELLA, «en caso de que todos los problemas internos estuvieran solucionados", el recuerdo de «dos misiones concretas que sólo vosotros podréis realizar», una «lograr la participación de los mejicanos, gestión que desde siempre quedó encomendada a la Junta del Centenario», y, otra, la gestión para que a través de las embajadas de Cuba en todos los países hispanoamericanos se logrará que los gobiernos crearan premios con destino a la bienal. (Carta a López isa del director del ICH fechada: Santiago de Chile, 2-xil-53). El mismo director remitía copia de esta carta al embajador de España en La Habana, JuAN PABLo LoJENDio, junto a otra misiva, fechada: Santiago 4-xII-53, donde le rogaba «que por todos los medios logres una decisión definitva sobre el problema porque no podemos estar tanto tiempo esperando una resolución que nunca llega... Me imagino que la situación política es delicada y que esto nos está originando un sinnúmero de dificultades. De todos modos aún me parece es tiempo de rectificar y hacerlo todo en Caracas si es que los obstáculos de Cuba se van haciendo insuperables". (Ambas cartas en AG, Secc. AA.EE., Caja 5379).

37 La propia Secretaría de la $\times$ Conferencia organizó una Exposición de Pintura Interamericana para su inauguración en el mes de marzo, a la par que gestionó el traslado a Caracas de la Sección Americana de Pintura de la bienal de Sao Paulo. A la altura de comienzos de febrero, ya se habian recibido con destino a la muestra obras de artistas de Ecuador, Haití, Panamá, Honduras, Santo Domingo y Paraguay y se esperaban de inmediato obras de Argentina, Brasil, Bolivia y Colombia (Véase ClaRISA SILvA: «Artistas de 6 paises ya mandaron obras para la Exposición de Pintura Interamericana. Posible traslado a Caracas de la Sección Americana de la Bienal de Sao Paulo», El Nacional, Caracas, 9-1l-54).

${ }_{38}$ El manifiesto se dirigía a la Comisión Nacional del Centenario de José Martí y lo firmaban los artistas: Amelia Peláez, Cundo Bermúdez, Mario Carreño, René Portocarrero, Julio Girona, Raúl Milán, Jorge Arche, Mariano Rodríguez, Manuel Roldán Capaz, Alfredo lozano, Agustín 
muy pronto lograron obtener un amplio respaldo y adhesión de intelectuales, profesionales y artistas no sólo de La Habana, sino también de otros lugares de la Isla ${ }^{39}$. Es más, la solidaridad y apoyo se recibió asimismo de artistas de otros países, que, como lo hicieron mexicanos, guatemaltecos, colombianos, argentinos, chilenos, uruguayos y españoles transterrados, enviaron escritos, manifiestos, cartas abiertas, telegramas, etc., solidarizándose con sus colegas cubanos y expresando su repulsa hacia la celebración de esta «iniciativa franquista» ${ }^{40}$.

Todo este clima de rechazo a la Bienal y los mismos retrasos en la terminación de la construcción del Palacio-Museo Nacional de Bellas Artes, obligaron a desplazar la fecha del 28 de enero fijada para la inauguración

Fernández, Romeho arciaga, Sandu Darie, Raúl Martinez, Felipe Orlando, Marta Arjona, Pablo Porras, fayad Jamis, hugo Consuegra, René avila, Guido llinás, luis Martín Pedro, Marcelo Pogolotti, José Mijares, Eugenio Rodriguez, Jesús Casagrán, Francisco antigua, Antonio Vidal, agustín, Cárdenas, Zilia Sánchez, Viredo, lucía Alvarez, Manuel Couceiro, Mo Mivares, Tapia Ruano, José I. Bermúdez, Jorge Camacho, Enrique Moret, luis Alonso, domingo Ravenet, Victor MANUEL, Mi ElenA JUBRías, PALKo LUKACS y otros ( No concurrirán a la Bienal Hispanoamericana los artistas cubanos», Noticias de Arte n. 11, La Habana, Oct.-Nov. 1953, pág. 15 y «Protestan los artistas plásticos de Cuba» en Uitraja la Memoria de Martí la Bienal Hispanoamericana. BOLETIN n. 1 , s/n. La Habana, s/f. Enero 1954, pág única.

39 Intelectuales, artistas y profesionales cubanos firmaron un escrito también dirigido a la misma Comisión respaldando las declaraciones e intenciones de los artistas citados; se encontraban entre los firmantes: Gladys laudeman, José Ardévol, Alicia Alonso, Fernando Alonso, José lezama lima, Salvador Bueno, Ma Teresa Freyre, luis amado Blanco, Conrado W. Messaguer, Harold Gramatges, Vicentina antuña, Félix Pita Rodríguez, Aurelio de la Vega, Juan David, Eva Frejaville, Alberto Bolet, Francisco Carone, Edgardo Martín, Julia Rodríguez Tomeu, Jose Ma valdés Rodríguez, Marta Frayde, nicolás Quintana, Raúl Roa, Rosa Oliva, mario Ronañach, argeliers león, Carlos mestre, Ricaroo Porro, Mario parajón, José Rodriguez Feo, antonio Rubio, Francisco Sierra, antonio Quintana, Carlos Vida.lo, Silverio Bosch, Nilo Rodriguez, J. Pino Zitto, Juan Blanco, Néstor, Almendros, Blanca Bahamonde, E. Collado, J.M. Rodriguez Cruz. Además, el 16 de noviembre de 1953, también había sido hecho público un manifiesto formado por intelectuales y artistas residentes en Santiago de Cuba en apoyo de "la justa protesta» firmado por M. Ferrer Cuevas, Francisco Ibarra, José Medina, Rafael M. Arcilagos, Felipe Salcines, Emiliano Ramos, Pedro E. Cañas Abril, M. Pujals, M. Céspedes, Baudilio Castellanos, Max Figueroa, Edmundo lópez, Hilda Orosa, Rafael Grillo, José antonio Portuondo, Manuel Alvarez, Justo Nicola, leonardo Griñán Peralta, Angel Díez, juan de Moya, dulce Maz Serret, antonio Ferrer Cabello, Mario Perdigó, René Valdés, Gloria

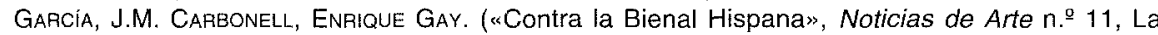
Habana, Oct.-Nov. 1953, pág. 16; "Adhesión de Intelectuales, Artistas y Profesionales de Cuba" y «Decalración de intelectuales y artistas de Santiago de Cuba« en Uitraja..., Op. cit.).

40 Así lo hacían los artistas mexicanos y españoles exiliados en México, aunque separados en dos grupos: por un lado los «artepuristas», como les llamó la prensa cubana, al frente de los cuales iba Rufino TAMAYO y que incluía a artistas españoles (es decir, el manifiesto que enviaron a la opinión pública cubana to firmaban Tamayo, Carlos Mérida, Alberto Gironella, Carlos Orozco Romero, Raúl anguiano, josé luis Cuevas, J. González Camarena, antonio Rodriguez luna, Arturo Souto, Enrique Climent, José Bartolí, Vlady, Enrique Echevarí́a, Machila Armida, fernando Belain, Alfonso Michel, Francisco tortosa, Ramón Gaya y héctor Xavier) y, por otro, 
tanto del edificio como del certamen, aunque los que se opinían a la celebración de la II Bienal no dejaron pasar tan significativo día en el calendario cubano y aprovecharon para inaugurar en él una muestra «anti-bienal», que se llamó «Exposición de la Plástica Cubana Contemporánea» (aunque popularmente se conoció como la «Anti-Bienal»), celebrada en el Lyceum Femenino del Vedado, en La Habana, y en la que se exhibieron más de setenta obras de unos cuarenta y tantos artistas cubanos, obras de acusada mirada hacia lo abstracto e intención de avance ${ }^{41}$.

No obstante, la incidencia de estos sucesos no hizo desistir a los gobiernos cubano y español de su pretensión, incluso el embajador de España en La Habana, Juan Pablo Lojendio, señaló al canciller español de Asuntos Exteriores - seguramente recordando las virulentas y provechosas polémicas que la I Bienal había ocasionado en Madrid- que el asunto contribuiría beneficiosamente a crear mayor expectación sobre la

un grupo más ligado al realismo social (Diego Rivera, David Alfaro Siqueiros, Xavier Guerrero, Leopoldo Méndez y José Chávez Morado). También desde Guatemala un grupo de artistas (Rodolfo Galeotti Torres, Roberto González Goyri, Rolando Palma, Victor Manuel Aragón, Roberto Ossaye, Arturo Martínez, Dagoberto Vázquez, Juan de Dios González) expresaron su rechazo al certamen en una carta abierta al pueblo de Cuba; igual lo hicieron otros grupos de artistas desde Colombia (Alipio jaramillo, Marco Ospina, Jorge Elías Triana, Eduardo Ramírez Villamizar, ignacio Gómez Jaramillo, Enrique Grau araujo, león Cano y jorge Moreno Clavijo), desde Argentina (Solari, Castagnino, Urruchúa, Biscione, Giustozzı, lbarra, Vigo, Devoto), desde Chile (Carlos Sotomayor, Gregorio de la fuente, Gustavo Poblete, Camilo Mori, Lyli Garafulic, María Fuenteal.ba), desde Uruguay (Armando González, Anhelo Hernández, el grupo plástico El Taller de TorRES GaRcia), etc. En el mismo sentido también se recibió un cable desde París apoyando la protesta y exposición «antibienal» que brotó de la oposición firmado por PABLO PICASSO, antoni Clavé, Joaquín Peinado, Baltasar lobor, Ismael de la Serna, Manuel angeles Ortiz, Hernando Viñes, Ceballos, Riba, Rovira, Mentor, Pizano y Orlando Pelayo. (Véase «los artistas de México se adhieren a la protesta", Noticias de Arte n 11, La Habana, Oct.-Nov. 1953, pág. 15; «De México», «De Guatemala» y «De Colombia» en Uitraja..., Op. cit.; "Los protestantes de la II Bienal en el Lyceum», Avance, La Habana, 27-i-54; «Exposición. Desagravio al Apóstol», Bohemia $n^{\circ}$ 5, La Habana, 31-1-54; "Cable de Picasso a los pintores cubanos que se oponen a La Bienal. Los secunda ampliamente», Tiempo, La Habana, 9-11-54, pág. 6; "Un vistazo critico sobre la Muestra del Lyceum», Avance, La Habana, 13-II-54; «Bienal y Antibienal», Bohemia, La Habana, 23-V-54, págs. 70-72).

41 La muestra permaneció abierta hasta el 14 de febrero y, entre otros, en ella figuraron los pintores amelia Pelález, René Portocarrero, Cundo Bermúdez, mario Carreño, julo Girona, Mariano Rodríguez, Victor Manuel, Pogolotti, Raúl Mijares, Martínez Pedro, Felipe Orlando, Sandú Darie..., los escultores Alfredo lozano, Eugenio Rodriguez, Pablo Porras, Jesús Casagrán, Enrique Moret, lucia Alvarez, Maria Miyares..., las ceramistas María Arjona y María ELENA. JuBRía y grupos como el jóven y destacado de «Los Once" (integrados por GuIdo LLINÁs, René Avila, hugo Consuegra, Fayad Jamis, Raúl martinez, José I. Bermúdez, tomás Oliva, Antonio Vidal, Viredo, Francisco Antigua y Agustín Cárdenas); artistas con los que también se solidarizaron los músicos y escritores ofreciendo con igual antención conciertos y recitales. (Véase: «Los protestantes...», Art. cit., 27-1-54; «Exposición. Desagravio...», Art. cit., 31-I-54; SALVADOR BUENO: «Los artistas cubanos rinden homenaje a MARTi», Carteles nº 6, La Habana, 7-II-54, págs. 
Bienal ${ }^{42}$. Como tampoco hizo que cejaran los «antibienalistas», quienes sumaron a la «Antibienal» de La Habana una campaña de protestas que llevó la exposición del Lyceum a Santiago de Cuba, donde fue acogida por la Universidad de Oriente, cuyo rector y bastantes de sus profesores habían hecho público ya su rechazo a la II Bienal, y, desde aquí, viajó más tarde a Camagüey. Mas, en la atmósfera de protestas levantadas ante la II Bienal, fue más significativa y trascendente la organización por la Federación Estudiantil Universitaria de La Habana -FEU - del Primer Festival Universitario de Arte Cubano Contemporáneo, inaugurado el 17 de mayo 24 horas antes que la "Bienal franquista»- en los salones de la Facultad de Derecho de la Universidad de La Habana, donde se exhibieron, antes de ser clausurado el 4 de junio, obras de cuarenta y dos artistas ${ }^{43}$.

Con todo $-\mathrm{y}$ a pesar del considerable apoyo y adhesión que tuvieron los actos y exposiciones "antibienal», altamente politizados- no se logró evitar que se celebrara la II Bienal Hispanoamericana en La Habana y, aunque sus organizadores se vieron obligados a retrasar en varias ocasiones la fecha anunciada ${ }^{44}$, la exposición fue inaugurada el 18 de mayo

34-35 y 92; A. AUGIER: «Los Anti-Bienalistas en el Lyceum. La Exposición de la Plástica Cubana en Homenaje a José MARTí y JORGE MAÑACH: «Plástica cubana en el Lyceum (A guisa de preludio)», Bohemia n 6, La Habana, 7-11-54, págs. 12-14 y 77; “Un vistazo crítico...», Art. cit., 13-11-54; J. MAÑACH: «Algo más sobre la exposición del Lyceum», Bohemia n 7, La Habana, 14-II-54, págs. 57 y $97-98)$.

42 Señalaba que la «Antibienal» no había tenido «éxito de público ni de crítica», pese a que algunas de las versiones de los diarios y revistas sostuvieran lo contrario; añadiendo: «Salvo algunas excepciones, las manifestaciones de arte abstranco han sido de condición mediocre y carentes, en la inmensa mayoría de los casos, de sinceridad. Creo que todo este incidente -la campaña y la exposición a que me refiero y el pequeño ruido producido en torno- contribuirá a aumentar la expectación por la Segunda Bienal y seguramente también al éxito de la excelente pintura que espero se presente en ella». (Despacho $n^{\circ} 34$ de fecha 19-11-54; AMAE, Leg. R-4262, Exp. 11, copia en AGA, Secc. AA.EE., Caja 5379).

${ }^{43}$ Véase «Bienal y Antibienal», Art. cit., pág. 71; «Festival Universitario de Arte. Contra una maniobra imperialismo franquista" España Republicana, Buenos Aires, 30-VII-54, pág. 5. Sobre la actuación y valoración antibienal en general véanse las referencias de SILVIA AMBROSIN:; "La Bienal Panamericana de Cuba y el Apóstol Martí, Ver y Estimar serie 2, $n^{\circ}$ 1, Buenos Aires, No. 1954, pág. 13; MARTHA DE CASTRO: El arte en Cuba, Miamai, Ediciones Universal, 1970, pág. 60 y Adelaida de JUAN: Pintura cubana. Temas y variaciones, México D.F., UNAM, 1980, págs.57-58.

44 Cuando se vió la dificultad de inaugurar La Bienal en 1953, se proyectó la fecha referida del 28 de enero de 1954, luego se dió la del 24 de febrero, más tarde la del 10 de marzo, se aludió posteriormente a otras en la segunda quincena de abril y, finalmente se fijó la del 18 de mayo, en la que fue inaugurada. El principal factor de los desplazamientos de fecha, aparte de los problemas políticos y la hostilidad de los artistas, fue el retraso en la construcción del Palacio-Museo de Bellas Artes, obra del arquitecto Alfonso Rodriguez PICHARdo (Gran Premio de Arquitectura de la ll Bienal), cuya terminación se encomendó a la Comisión del Centenario de Martí. Ya el presidente BATISTA había inaugurado simbólicamente el Museo el 28 de enero, al clausurar el Año Martiniano, pero la inauguración real no tuvo lugar hasta el 18 de mayo junto a la de la II Bienal. 
por el presidente de la República, el general Fulgencio Batista. Los partidarios del certamen, sin dejar de lamentar las ausencias, arguyeron en su defensa, como lo hacía el ministro cubano de Educación, Francisco Ichaso, tanto la neutralidad política de la cultura y el arte como la especial vinculación entre América y España ${ }^{45}$. Por otro lado, la postura oficial frente al boicoteo, aplicando ciertas medidas, finalmente obtuvo la participación de un número de artistas cubanos y extranjeros realmente muy elevado ${ }^{46}$.

La concreta participación de Venezuela en esta tempestuosa edición del certamen, que se mostró bastante remolona desde sus comienzos, hubo de ser alentada por la diplomacia española. Se inició la actividad en Venezuela a mediados de enero de 1954 , cuando con prisa -en la idea de que la Bienal se inauguraría a finales del mismo mes- la Dirección de Cultura y Bellas Artes del Ministerio de Educación hacía público un aviso oficial convocando a los artistas venezolanos a presentar

45 «La magnitud y transcendencia - señaló- de este evento sólo pueden ser negadas por una furibunda pasión sectaria. Los cuadros, las esculturas, las piezas de cerámica, los proyectos arquitectónicos que se exhiben en esta Bienal no responden a ninguna tendencia política. La misma pluralidad que se advierte en los estilos, se advierte en los temas, y existe con toda seguridad en la mente, en la sensibilidad y en la conciencia de los expositores. Me parece absurdo abscribir a un régimen determinado a los artistas y a los hombres de letras... Pedirle (al artista) cuentas porque realice su obra bajo este régimen o bajo el otro y condenarlo al ostracismo porque no vive en una determinada atmósfera cívica, constituye la mayor de las injusticias. (...). Las diferencias de carácter político no pueden cortar las relaciones entre pueblos y mucho menos las relaciones culturales. / La política pasa, el espíritu queda. A despecho de todos los alejamientos circunstanciales, España y nuestra América forman parte de un mismo orbe cultural. Unicamente no lo reconocen así los que quisieran ver a nuestro continente invadido por otra cultura, por una cultura no cristiana, no grecorromana, no heredera de España, y que tendría siempre para nuestros cuerpos y para nuestras almas un carácter postizo e inmovilizador. / Es penoso que en esta Segunda Bienal, donde hay envios excelentes, no estén representados, por escrúpulos politicos, algunos de nuestros buenos pintores y escultores. No es imputable el hecho a los organizadores. La convocatoria se hizo con toda liberalidad. A nadie se le ha preguntado por su filiación ideológica para admitirle una obra» (F. ICHASO: «Acotaciones. Museo y Bienal», Diario de la Marina, La Habana, 20-V-54. En sentido parejo véase GASTÓN BAQUERO: «La inauguración de la II Bienal Hispanoamericana de Arte», Diario de la Marina, 18-V-54; MIGUEL DE MARCos: «ltinerario. Biografía de un Museo", Diario de la Marina, 20-V-54; ADELA JAUME: «El Museo, La Bienal de Arte y el Presidente, general Batista», Diario de la Marina, 20-V-54).

46 Las cifras oficiales hablaron de 18 paises representados, 3525 obras a concurso y 200 en salas especiales. hay que tener en cuenta, sin embargo, la amplia intención de alcanzar éxito numérico que se adjuntó al certamen, así como la intención de darle mayor tono y prestigio nacional, para lo que se unió a la II Bienal el viı Salón Nacional de Arte de Cuba -que aumentó en gran número la participación y tuvo el mismo Jurado que La Bienal- y las retrospectivas de los artistas cubanos fallecidos Armando G. Menocal, Fidelio Ponce de León y Leopoldo Romañach, que tuvieron una sala cada uno. No se consiguió, con todo, que concurrieran entre las casi dos mil obras reunidas, de las que hablaron otras fuentes desglosando adheridos, las de algunos de los 
sus obras ${ }^{47}$. Aunque según el embajador de España en Caracas, Gonzálo de Ojeda, pese a que los organizadores de la II Bienal habían estado directamente en contacto con aquella Dirección de Cultura para la participación venezolana, el tiempo había pasado sin que ésta «nombrase un Jurado calificador de obras a enviar, ni se publicase ninguna noticia en la prensa acerca de la misma» y, dado que se acercaba su fecha de inauguración, "el Secretario de esta Embajada tuvo que dar los pasos pertinentes cerca de la Dirección de Cultura del Museo de Bellas Artes para que se convocase, de urgencia, a todos aquellos artistas en pintura, escultura y arquitectura que deseen concurrir al mencionado certamen, encargándose al mismo tiempo del recibo y calificación de las piezas y de su inmediato envío a La Habana»; añadiendo sobre la aportación a que daría lugar esta precipitada convocatoria y la pasividad mostrada por la oficialidad venezolana: "Y dada la premura con que ésta (la convocatoria) se ha realizado, no espero que la participación venezolana pueda ser muy brillante. Al igual que el año pasado, las piezas llegarán tarde y no podrán figurar, ni tan siquiera, en el catálogo que debe estar editándose ya para estas fechas. Este retraso, como en la pasada ocasión, se debe a la indolencia del Ministerio, así como a determinada camarilla de artistas que no ven con buenos ojos estas exhibiciones. Siendo precisamente este grupo el que más bulle, y en el que recaen por regla general todos los premios de las exhibiciones locales, ya que forman parte de todos los Tribuinales calificadores, no es de extrañar que no se haya dado demasiada prisa en organizar todo lo que a la Bienal se refiere» ${ }^{48}$.

más interesantes artistas cubanos del momento por las razones ya comentadas, vacio semejante, recordando otras grandes oposiciones extranjeras, al que dejaron los artistas mexicanos y españoles exiliados en México. Por el contrario, sí se logró que participara en esta II Bienal Hispanoamericana un notable grupo de artistas españoles exilidos o residentes en París (al certamen acudieron Oscar Domíngez, Pedro Flores, Ginés Lieban, Xavier Oriach, Emilio Grau Sala, Francisco alcaraz, Francisco boadella, Juan a. Roda, maria Girona, M. Andreu, alejo Hinsberger, A. Martin Romo, A. Uria Monzón, Xavier Valls, August Puig, J.L. Rey-Vila, Vidal Quadras, Carlos García González y Carlos Sansegundo) e incluso alguna de las recompensas más altas que ofrecía el certamen - el Gran Premio Ciudad de La Habana- recayó en Pedro Flores.

47 La convocatoria decía: «Ministerio de Educación / Dirección de Cultura y Bellas Artes / Museo de Bellas Artes / Se participa a los piritores, escultores y arquitectos venezolanos que I 28 del mes en curso se inaugurará en La Habana la II Bienal Hispanoamericana de Arte. Los Artistas que deseen concurrir a dicha Exposición deberán enviar sus obras al Museo de Bellas Artes los días 18, 19, 20 y 21, improrrogables, el presente mes. Caracas, 16 de enero de 1954» (Publicada en El Universal, Caracas, 17-I-54; La Esfera, Caracas, 17-I-54; Ultimas noticias, Caracas, 17-I-54).

48 Finalmente añadía que en los contactos directos de la Embajada con los artistas venezolanos que habian tomado parte en la I Bienal, recomendándoles participaran en la nueva edición, todos habían puesto de manifiesto "que no habian tenido ninguna noticia con respecto a la II Bienal, y por tanto muchos de ellos no tienen en este momento piezas que exponer, ya que no 
Más, ahondando en los juicios que hacía el embajador español sobre las causas de la actitud oficial venezolana respecto a la aportación a la II Bienal, sin duda resulta mucho más interesante la ampliación sobre los mismos que remitía en un despacho reservado de comienzos de febrero, donde hablaba de una "pasividad estudiada", que intentaba explicar aduciendo consideraciones sobre el estado del arte en Venezuela - «intimamente —decía - ligado a una política izquierdista»-, algo extensivo a "estos paises nuevos, sin historia ni tradición artística, (donde) es corriente ver a los nuevos Mecenas imbuídos de concepciones extremistas y amantes de todo lo que pueda suponer renovación y «progreso»... afán «snob», pero (que) indudablemente hace el juego de aquellos otros que manejan la tramoya entre bastidores". Así pues, comenzaba Ojeda por señalar en adición a su despacho anterior y considerando oportuno no acudir a la II Bienal:

«tengo la honra de comunicar a V.E. que las piezas recibidas en el Museo de Bellas Artes para ser enviadas a la II Exposición Hispanoamericana de Arte, alcanza el exiguo número de 12. Hechas las oportunas averiguaciones, se ha comprobado que el Director del Museo de Bellas Artes, sin duda siguiendo instrucciones de la Dirección de Cultura, aconsejaba a los artistas que allí se presentaron, que no remitieran ninguna obra a la II Bienal, ya que, como en la pasada ocasión, «no se había tenido en cuenta Venezuela para nada, ni se le había comunicado con tiempo la fecha de este certamen».

Por mi Despacho antes mencionado ( $\mathrm{n}^{\circ} 40$ de fecha $21-1-54$ ) informaba a $V$. E. que estas asertaciones eran falsas, ya que tienen conocimiento de la inauguración de la II Bienal desde hace muchos meses. Ha existido, sin duda, una pasividad estudiada, con objeto de no asistir al certamen. Esto hace pensar que en la I Bienal de Madrid ocurrió algo parecido, ya que Venezuela envió sus piezas mucho después de inaugurada dicha Exposición y por motivos que no han sido todavía muy justificados.

Dada la pequeña cantidad de obras presentadas, se ha considerado oportuno no acudir a la II Bienal, ya que dichas obras no representan un exponente del desarrollo artístico en Venezuela» ${ }^{49}$.

estaban preparados para ello». Pero la Embajada no había querido «intervenir directamente en los preparativos de la Bienal, porque había recibido instrucciones de ingerirse lo menos posible en el asunto, por temor de que algunos sectores pudieran darle un carácter político" (Despacho n 40, fechaso: Caracas, 21-1-54. AmAE, PLEG. R-4262, ExP. 11).

49 La argumentación del embajador continuaba, ampliando la información de su despacho $n^{\circ}$ 40 , insistiendo en la existencia de «una camarilla de artistas que no ven con buenos ojos estas exhibiciones, ni nada que se refiera a España... que es el grupo que tiene más propaganda oficial y que forma parte de todos los tribunales calificadores, que se reparte los premios y que constituye una verdadera masonería en el arte". Era curioso observar, añadia intentado definir en que consistía su arte, «como quiere imitarse cualquier tendencia artística moderna, tal como se siuge y estudia en Francia a PICASSO» y acudía a entresacar algunos comentarios de un artículo del pintor 
Con todo, las gestiones continuaron para conseguir una participación más activa del gobierno venezolano y una selección más amplia, aprovechando incluso la confirmación oficial de este gobierno de su participación en la Bienal y el paso por Caracas del embajador de España en Cuba, Juan Pablo Lojendio, en el sentido de "realizar en esa (ciudad) alguna gestión en favor de la Bienal para que efectivamente el envío sea de im-

Alejandro Obregón (publicado en La Esfera, 26-l-54) intentando explicar las nuevas tendencias, para añadir: "Simplemente estas frases, elegidas entre las muchas del artículo de este pintor, nos hacen recordar con sus palabras «impersonal», "gregario", "masa", "anónimo", etc. a las concepciones de la propaganda comunista. Aunque en la Rusia soviética no se acepta con facilidad esta pintura, habiendo tenido dificultades el gran maestro (Picasso), a consecuencia de su retrato de STALIN, es de ver como progresa en los paises de cultura occidental y apoyada por aquellos elementos muy avanzados en política que, si no cumunista, constituyen lo que se ha llamado «compañeros de ruta». ¡Tal vez la URSS que ha destruido aquellos pilares fundamentales, en donde se basa la cultura occidental (religión, familia, respecto a la dignidad humana, etc.), aproveche estas tendencias para destruir la emoción artística, otro de los pilares «burgueses»! En consecuencia, señalaba sobre la situación concreta del país: «En Venezuela existe la Escuela de Artes Plásticas, que representa aquí lo que en Madrid es la Escuela de Bellas Artes. Aunque dicha Escuela está completamente influída por pintores de tendencia izquierdista, no contentos con ello, éstos poseen otro Centro, con apoyo y presupuesto oficial llamado «Taller Libre de Arte». Dicho Centro constituye más un círculo político que artístico. Su entrada es reservada a determinadas personas y de allí salen muchas consignas y propaganda. El Arte, pues, en Venezuela, está íntimamente ligado a una política izquierdista. Es difícil progresar si no se pertenece a este grupo. La propaganda oficial en la prensa, en las conferencias, en las exposiciones, y en toda clase de manifestaciones artísticas, está influída por ellos. No hay contrato importante del Gobierno en donde estos artistas no tomen su parte de León. / Estas tendencias revolucionarias en el arte las vemos en muchos de los murales de la nueva construcción de la Ciudad Universitaria, cuya Biblioteca, aula magna, y otras dependencias, serán la Sede de la x Conferencia Interamericana. Su gusto moderno, artísticamente hablando, es de pesadilla. / Muchos de los artistas independientes están indignados con esta dictadura del arte y piensan realizar una contra-propaganda poniendo al descubierto algunas de las tramas de estos Organismos Oficiales. Naturalmente que algunas personas influyentes les apoyarán... Es muy difícil para ciertos sector de pintores que les puedan ceder un Salón en el Museo de Bellas Artes para efectuar una Exposición o que una de sus obras obtenga un premio o sea elegida para presentación de un certamen». Argumentación junto a la que remitía «una lista de pintores y escultores de Venezuela, aunque no completa, reseñando sus direcciones y sus tendencias. Los señalados con una letra (c), son comunistas manifiestos. Aquellos señalados con la letra (a), constituyen el grupo abstraccionista, apoyado también por aquellos pintores cuyo nombre figura subrayado. La Srta. ElisA E. ZuLuAGA, que figura en la Isita en subrayados, y con la letra (p), es la Presidenta de toda esta Asociación moderna de pintura. Por su cargo en la Dirección de Cuitura y por sus ideas simpatizantes con la extrema izquierda (llámese comunismo), constituye la Sita. ZuLuAGA una animadora importante del grupo de pintores antes mencionado». La adjunta "Lista de pintores y escultores de Venezuela», pues, relacionaba a los siguientes artistas: Pablo Benavides, Pedro Centeno, José Canelones, Francisco Fernández, Federico Fischel, (c) Manuel Vicente Gómez, Jonic Miloc, Halyna Mazapa de Koval, Hugo Matthes, Carlos Otero, Manuel Cabré (Dir. de Cultura y Bellas Artes), Luis LÓPEZ MÉNDEZ (Dir. de Cultura y Bellas Artes), (c) Eduardo Francis, Santiago Poletto (Escultor), (c) Julio C. Rovaina (Liceo andrés Bello), Raúl Santana, Viterbo Garcia, Pedro A. González (Escuela de Artes Plásticas y Aplicadas), Raúl Moleiro, Ernesto Maragall (Escuela de A.P. y A.A. Escultor español), Rafael Monasterios, Charles Ventrillons (Escuela de Ingeniería. Ciudad Universitaria), Antonio L. Alcántara, armando lira, Eduardo Gonzál.ez, albeto Egea (Asoc. de 
portancia» ${ }^{50}$. Y, efectivamente, la representación venezolana consiguió aumentarse ostensiblemente sobre la pequeña aportación que señalara Gonzalo de Ojeda; de modo que en la Bienal de La Habana estuvieron Antonio Alcántara, Armando Barrios, René Boissonnas, Manuel Cabré, Marcos Castillo, Pedro León Castro, Alfredo Chacón Espinosa, J.Vicente Fabbiani, Federico Fischel, Tomás Lorenzo Golging, Pedro Angel González, Rafael Ramón González, Luis A.López Méndez, Mateo Manaure, Rafael Monasterios, Francisco Narváez, Carlos Otero, Manuel S.Pérez, Héctor Poleo, César Prieto, César Rengifo, Armando Reverón, Oswaldo Vigas y Elisa Elvira Zuluaga; es decir, 24 artistas, entre quienes se insistía en algunos que ya habían figurado en la I Bienal (Alcántara, Castillo, P.A.González, R.R.González, Monasterios, Narvaez, C.Otero, Prieto), pero se añadían nombres nuevos, entre los cuales Héctor Poleo -que, sin embargo, en 1951 había participado en la «contrabienal» de París- obtuvo por su óleo "Los tres comisarios» un premio de 500 pesos instituído por el Gobierno de Cuba ${ }^{51}$.

Este nuevo entendimiento y actitud cooperadora entre los gobiernos español y venezolano que, finalmente, se reflejaba en la participación en la II Bienal, tendría además muy pronto una nueva plasmación con la invitación del Gobierno venezolano a exhibir en Caracas la Exposición Antológica de

Pintores Independientes), César A. Cordero, (c) Gabaiel Bracho (Asoc. de Periodistas), Vicente Fabbiani (Asoc. Pintores Independientes), (a) Otero Rodriguez (Abstraccionista. Escuela de A.P. y A.A.), (a) MATEo MANAURE (Abstraccionista. Escuela de A..P. y A.A.), (c) HÉctor Poleo (Museo de Bellas Artes), (c) CÉSAR RENGIFO (Taller Libro de Arte), (c) ARMANDO BARRIOS (Abstraccionista. Taller libre), Tomes L. Golding, Eduardo Schlageter (Dirección de Cultura), (p) Elisa E. ZULOAGa (Dirección de Cultura), Gregorio Garcia, Rafael Ramón González, César Prieto, Alejandro Colina (Escultor), Francisco Narvaes (Director Escuela de A.P. y A.A. Escultor), Pedro Blanco, augusto Pereira (Escuela de A.P. y A.A.), (c) Rafael Rosales (Taller Libre de Arte), Aramando REVERÓN (Asociación de Pintores Independientes), Manuel Pérez (Taller Libre de Arte). (Despacho Reservado n 101, fechado: Caracas, 6-II-54. AmAE, Leg. R-4262, Exp. 11).

50 El grabador Julio Prieto Nespereira, delegado español de la Bienal en La Habana, escribía a comienzos de marzo a LOJENDIO, que se encontraba -en esos momentos de celebración de la $\times$ Conferencia Interamericana- en Caracas, informándole del ascenso del ritmo de trabajo en la terminación del Palacio de Bellas Artes, lo que haría casi «seguro que la fecha de inauguración esté comprendida entre el 17 y el 20 de abril» y de que habia recibido una misiva de SÁNCHEZ BeLla en la que le decia: «Recibí una carta del Embajador de Venezuela en Madrid, Don Simón BECERRA, en la que me comunica que su Gobierno ha decidido participar en la Bienal y que está ya verificándose la selección y que pronto se enviarán las obras a La Habana. La comunicación tiene carácter oficial y, por lo tanto, puedes hacerla pública»; añadiendo que, con esta noticia podría aprovechar su estancia en Caracas para efectuar las gestiones aludidas. (Carta de PRIETO NesPereira al marqués de Vellisca fechada: La Habana, 8-11-54; AGA, Secc. AA.EE., Gaja 5379).

51 Todos los artistas del envio participaron con una sola obra y en la sección de Pintura al óleo, salvo Alcántara que participaba con tres, Boissonnas que lo hacia con dos y Manuel $S$. Pérez que participaba con dos obras en la sección de Pintura al agua y al pastel. (Véase el catálogo general // Bienal..., Op. cit., págs. 169-171; sobre los premios págs. LI-LIX. 
este certamen, preparada para realizar una jira por Iberoamérica y que previamente había sido ya expuesta en Ciudad Trujillo - Santo Domingoentre del 24 de octubre al 14 de noviembre de 1954 52; invitación, por otro lado, incentivada desde la misma Embajada de España en Caracas ${ }^{53}$.

A mediados de diciembre, solicitaba el nuevo embajador de España en Caracas, Manuel Valdés, marqués de Avella, que se reexpidiera a Venezuela toda la aportación del país a la II Bienal ${ }^{54} \mathrm{y}$, por entonces, llegaban también a Caracas el poeta Leopoldo Panero y Luis González Robles, secretario y vicesecretario generales de la Bienal, para organizar la muestra antológica de más de trescientas obras que se pensaba inaugurar a principios de enero en el Museo de Bellas Artes patrocinada por la Dirección de Cultura y Bellas Artes del Ministerio de Educación venezolano y bajo los auspicios de la Embajada de España ${ }^{55}$. Y efectivamente, el día 9 de enero el coronel Marcos Pérez Jiménez inauguraba la Muestra Antológica de la II Bienal en el Museo de Bellas Artes, en un acto que el embajador de España describía así al ministro de Asuntos Exteriores:

«Entre las personalidades que asistieron al Acto figuraban los Ministros de Educación Nacional, Relaciones Exteriores, Comunicaciones, Relaciones

52 Sobre la muestra antológica de Santo Domingo véase el catálogo Muestra Antológica de la II Bienal Hispanoamericana de Arte en Ciudad Trujillo. Ciudad Trujillo 24 de Octubre de 1954, Ciudad Trujillo, Ed. del Caribe, 1954.

53 A finales de agosto de 1954, el encargado de negocios a. i. de España en Caracas, JosÉ LUIS LITAGO, escribía a AGUSTÍN DE FoXÁ, encargado de negocios de España en La Habana, preguntándole por el regreso de los cuadros que Venezuela había aportado a la II Bienal o si ésta había iniciado en la República Dominicana su jira por América, para poder transmitir la información a los pintores interesados que le habían preguntado. (Carta fechada: Caracas, 25-VIII-54). A esta responderá el conde de FoxÁ que se había puesto en contacto con el secretario general de la Bienal, LeOPOLDO PANERO, quien le habia informado «que están esperando la invitación oficial del Ministerio de Educación de Venezuela para llevar a este país una Exposición Antológica de la Bienal»; añadiendo: «Convendría, por lo tanto, que gestionases de ese Ministerio esta invitación. De aquí saldrá la Bienal (reducida) para la República de Santo Domingo, donde se inaugurará en Ciudad Trujillo aproximadamente hacia el 24 de octubre permaneciendo en dicha República hasta últimos de noviembre o primeros de diciembre, que es cuando piensa ir a Venezuela" (Carta fechada 17-IX-54). Ambas cartas en AGA, Secc. AA.EE., Caja 5379.

54 Telegrama fechado 17-XII-54 dirigido al embajador de España en La Habana solicitando que se embarcará esta aportación el 21 de diciembre en el "Marqués de Comillas". JUAN PABLO LOJENDIO con fecha 24-XII-54 le contestaba confirmándole la salida de los cajones con esa aportación rumbo al puerto de La Guaira en tal fecha. (AGA, Secc. AA.EE., Caja 5379).

55 Véase sobre la llegada de Panero, Gonzalez RoBles y Pedro Roselló, así como algunos comentarios sobre la organización de la muestra, que especialmente incidieron en su patrocinio y los paises representados, destacado lo numeroso de aportación española y algunos de sus pintores, «Llegó LeOPOLDO PANERo a Organizar Muestra de Bienal Hispanoamericana», El Universal, Caracas, 17-XII-54; "Muestra de la II Bienal Hispanoamericana de Arte», El Universal, Caracas, 31-55, pág. 1; «En la Muestra de la II Bienal Hispanoamericana se destaca el aporte de la pintura española», El Universal, Caracas, 5-l-55. 
Interiores, Obras Públicas, Minas e Hidrocarburos y Sanidad. También los Directores Generales de Cultura, de Seguridad, Ayudantes del Presidente de la República, Jefe de Protocolo y Director del Museo de Bellas Artes.

Asistí a la inauguración acompañado de los funcionarios de esta Embajada y Consulado General, habiendo invitado a un nutrido grupo de la Colonia Española en Caracas. En este acto hice entrega al Presidente de la República de un cuadro de Lucas Villasmil titulado «El Monasterio de las Huelgas", exponiendo en un breve discurso mi agradecimiento por la asistencia del Presidente que había dado tanto realce con su asistencia. Puse también de relieve el constante anhelo de superación del Gobierno de Venezuela, no sólo en aquello que atañe a lo material sino también en todos los capítulos referentes a lo cultural, artístico e intelectual. Hice ofrenda del mencionado cuadro al Presidente como un homenaje de los pintores españoles a su persona.

El Presidente agradeció con sentidas palabras la ofrenda, añadiendo que estaba gustoso en prestar su colaboración a cualquier demostración de hispanidad que tanto reflejaba la fuerte cohesión que existe entre España y Venezuela» 56 .

La prensa caraqueña, se hizo también gran eco del acontecimiento, comentando el acto inaugural —reseñas del cual pronto también aparecieron en los diarios españoles - y ofreciendo diferentes datos sobre la celebración de la Bienal en La Habana y la Antológica que ahora se traía a Caracas ${ }^{57}$. Ocupaba la muestra cuatro salas del citado Museo, tres de artistas españoles y una de artistas latinoamericanos, y el mismo catálogo editado para la ocasión aclaraba: «La Segunda Bienal Hispanoamericana de Arte se inauguró en La Habana el 18 de Mayo de 1954, clausurándose el 10 de Septiembre del mismo año. Se exhibió un total de 1829 obras, distribuidas en las secciones de Pintura al Oleo, al Agua y al Pastel, Dibujo, Grabado, Escultura, Cerámica y Arquitectura. La presente Muestra Antológica ha sido realizada entre los artistas premiados en la primera y segunda Bienal y entre aquellos otros que sin haberlo sido fueron propuestos para una recompensa al menos por tres Miembros del Jurado", catalogando después 325 obras de 175 artistas, de los cuales, cinco eran argentinos, tres bolivianos, tres brasileños, veintiuno cubanos, uno ecuatoriano, noventa y siete españoles -con 232 obras-, tres estadounidenses, tres filipinos, cinco haitianos, tres jamaicanos, uno

56 Despacho $n^{\circ} 18$ fechado: Caracas, 10-I-55. Amae, Leg. R-4842, Exp. 111.

57 Véase «Una Exposición Antológica de Arte Hispano-Americano se inaugura hoy en el Museo de Bellas Artes», El Nacional, Caracas, 9-1-55, pág. 34; “A la Muestra de la II Bienal asistió ayer numeroso público», El Universal, Caracas, 10-1-55; «Inauguración de la Exposición Antológica de la II Bienal Hispanoamericana de Arte, en Caracas», Abc, Madrid, 14-I-55; «Se inaugura en Caracas la II Bienal Hispanoamericana", Ya, Madrid, 14-I-55. 
panameño, dos peruanos, cuatro dominicanos y veintidós venezolanos con una obra cada uno ${ }^{58}$. Ocasión que también fue aprovechada tanto para exhibir en el mismo Museo obras españolas no contemporáneas (tapices, retablos, Fortunys, etc.) o incidir en el comentario de algunas obras

58 Véase II Bienal Hispanoamericana de Arte. Exposición patrocinada por el Ministerio de Educación. Dirección de Cultura y Bellas Artes, Caracas, Museo de Bellas Artes, 9 al 30 de enero de 1955; (Imprenta Nacional), s./ paginar. Este catálogo de la Antológica relaciona a los artistas: argentina (7 obras): Julo Barragán, Arturo Gerardo Gustavico, Maria Valencia, Beatriz Varela y Elba VILLAfañe (p); BOLIVIA (3 obras): Jorge Carrasco, María Luisa Pacheco (p) y José

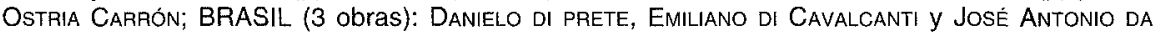
Silva ( $p$ ); Cuba (30 obras): Osvaldo Cabrera, Ma Teresa de la Campa ( $p$ ), Mirta Cerra ( $p$ ), Mauricio Collada, Joaquin Ferrer Marouinez, Simcho Glezer, Carmelo González (p), Ana Rosa G. de González, Glyn Jones ( $p$ ), Manuel Guerra, Felipe lópez, luis Peñalver ( $p$ ), Armando Posee (p), Caridad Ramirez, fausto Ramos, arnaldo Ravelo, Juan Sánchez, Daniel Serra Badue (p); Carlos Sobrino (p), Lesbia Vent dumols y Otto Zimmermann; ECuAdoR (2 obras): Manuel Redón (p), España (232 obras): José Aguiar, Marcos Aleu (p), Salvador de Aulestia, Rafael. Alvarez Ortega, josé amat (p), Ricardo Arenys, Manuel Baeza, Xavier Blanch, Emilio Bosch Roger, Juan Brotat, josé Caballero (p), Domingo Carles, josé Clará (p), Juan Commelerán, Modesto Cuixart, Alvaro Delgado (p), Francisco Domingo (p), F. Esteban, Ramón Figueras, Pedro Flores (p), Juan Fluviá, Juana Concepción Francés, Amadeo Gabino (p), Menchu Gal (p), luis García Ochoa, fermín González Prieto, luis M a Güell, Antonio Guijarro, Pedro Gusinye, Manuel Humbert $(p)$, José Hurtuna, Alcira ibañez, Ramón isern, Juan Guillermo, antonio lago Rivera, josé lapayese del Río, Carlos Pascual de lara (p), antonio López Montenegro, López Ramón, Ricardo lópez Santamaría, Francisco lozano, Rafael llimona, Federico lloveras, Ricardo Macarrón, josé Ma mallol Suazo, Joaquín Marsillach, Cirilo Martínez Novillo (p), Francisco Mateos, Federico Molina, José antonio Molina Sánchez, Juan Antonio Morales (p), Sofía Morales, luis Muntané, Carlos Nadal, Gregorio del Olmo, Alfredo Opisso, Godofredo Ortega Muñoz ( $p$ ), Benjamín Palencia ( $p$ ), Alfredo Palmero, Jesús de Perceval, Ramón Pichot, Enrique Planasdurá, José Ma Prim, Pedro Quetglás (p), Agustín Redondela (p), Ramón Reig, Manuel Rivera hernández, L. Rodríguez, San climent, Ramón Rogent, R. Rollán, Bernardo San Juan, $M^{2}$ Dolores sánchez diaz, Enrique Segura, Francisco Serra, Juan Serra, J. Serranos, Alfredo Sisquella, Joaquín Sunyer, Manuel Surroca, Antonio Tapies, José Tapiola, joaquín Tarruel.la, Delhy Tejero, Francisco Todó-García, José de Togores, Juan Torrás, Agustín ubeda, Santiago Uranga, EVafisto Valles, Joaquin Vaquero Palacios, Joaquín Vaquero Turcios, Daniel Vázouez Díaz (p), Ramón Vázouez Molezún, Miguel Villa, Vicente Viudes, Mario Vives y Rafael Zabaleta;

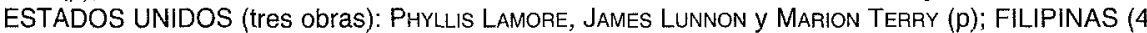
obras): Vicente S. Manansala, Nena Sagull y Fernando Zóbel de Ayala; AHITI (5 obras): Rigaud Benoit, Dieudonne L. Cedor ( $p$ ), Adam Leontus, Philome Obin y Frederic Pierre; HOnduras (2 obras): Armando Morales (p) y Miguel Angel Ruiz Martínez (p); JAMAiCA (3 obras): Anna hendricks, Albert Huie (p) y L. Van Pitterson; PANAMA (1 obra): Justo Arosamena (p); PERU (3 obras): Ricardo Grau y Ernesto Nieto; RePublicA dominicana (4 obras): Mounia L. Andrade, Silvano lora (p), Yory Morel y Mercedes Rodríguez; VeneZuela (22 obras): Antonio alcantara, Magda andrade, armando Barrios, Manuel Cabré, Marcos Castillo, Juan Vicente Fabbiani, Tomás lorenzo golging, Pedro Angel Gonzalez, Rafael Ramón González, Pedro león Castro, luis A. López Méndez, Mateo Manaure, Rafael Monasterios, Francisco Narváez, Carlos Otero, Manuel S. Pérez, Héctor Poleo (p), César Rengifo, Armando Reverón, Oswaldo Vigas y Elisa ELVIRA ZULUAGA. (Los artistas señalados con una «p» habian sido galardonados con algún premio en la Bienal). Por otro lado, las obras que se exponían los artistas venezolanos, casi la misma que en La Habana, según El Nacional eran de «pertenencia de nuestro Museo de Bellas Artes» («Una Exposición...». Art. cit., 9-I-55, pág. 34). 
y motivos ${ }^{59}$ como para servir a los intereses de la diplomacia ${ }^{60} 0$ intentar la venta de algunas de las obras, sentido que, junto a la abundante asistencia y general éxito de la muestra, era el que especialmente remarcaba en su crónica Angel Vilches ${ }^{61}$.

Mientras la selección antológica de la II Bienal iba acabando su recorrido por América y en España se hablaba poco criticamente de su «magnífica acogida», «el éxito» y «la oportunidad y acierto» de su actuación en aquel continente ${ }^{62}$, se comenzaba también a organizar la III Bienal Hispanoamericana. La sede de Barcelona elegida para celebrar esta tercera edición, que intentaría devolver el ritmo bianual al certamen y que iba a ser la última de las que pudieron llevarse a efecto, ya había sido anunciada en 1952, al término de la Exposición Antológica de la I Bienal celebrada en la Ciudad Condal, justificándose en la estrecha y tradicional vinculación del lugar con el arte avanzado. Fue, pues, celebrada entre el 24 de septiembre de 1955, día de la barcelonesa festividad de la Merced y en el que un nuevo discurso del ministro de Educación Nacional, Joaquín Ruiz Giménez, la dejó inaugurada, y el 26 de enero de 1956, fecha de su clausura y a partir de la cual se comenzó a preparar la exposición antológica

59 Véase «Muestra de la li Bienal. Rubén Dario, de monje cartujo, visto por DANIEL VÁZUEZ DíAZ», El Universal, Caracas, 17-|-55; «Termina esta semana de la muestra de la II Bienal Hispanoamericana», El Universal, Caracas, 24-I-55.

60 Así por ejemplo, el embajador de España y su esposa, la marquesa de Avella, organizaban para el 26 de enero, una visita «en el Museo de Bellas Artes, dedicada especialmente al Cuerpo Diplomático y la Sociedad venezolana. En el curso de la visita el laureado poeta y crítico de Arte, Don Leopoldo Panero, disertará sobre las Escuelas y tendencias pictóricas de las obras expuestas" (Véase las tarjetas de invistación extendidas por el embajador de España y la marquesa de Avella con fecha 22-1-55). Registro General de la Agencia Española de Cooperación Internacional -en adelante citado RGAECl-, Caja 250.

61 Señalaba, poco críticamente e insistiendo de contínuo en el éxito de la muestra, que ésta era visitada por más de un millar de personas a diario, «elevándose esta cifra a cinco o seis mil los domingos", lo que decía que no era extraño porque en Caracas existía una buena trađición de compradores e importantes colecciones - como las de Alejandro de Pietri, Pedro Vallenilla, inocente Palacios, Boulton, Juan RHOLL-; añadiendo en este sentido: «El ministro de Educación, por su parte, ha nombrado una Comisión - constituída por los coleccionistas JUAN RHOLL y PEDRO Vallenilla, el pintor Graciano Gasparini, el arquitecto Carlos Raúl Villanueva y el director del Museo de Bellas Artes, doctor CARLOS OTERO-, que dictaminará sobre la adquisición de un lote de cuadros con destino a este último centro». Citaba también entre los artistas españoles que, según su «observación personal obtenida en el diario recorrer de las salas», más habían llamado la atención a Benjamín Palencia, Vázquez diaz, Enrique Segura, Vázouez Molezún, luis Maz Güell; Muntane, Carlos Pascual de lara, antoni Tàpies, Gregorio del Olmo y Joaquín Tarruella, agregando, en cuanto a las adquisiciones, que «se calcula que unos cuarenta de los cuadros expuestos quedarán en Caracas, engrosando las colecciones particulares a las que al principio nos referíamos» (A. VILCHES: «Mañana se clausura en Caracas la Exposición de la II Bienal Hispanoamericana», Arriba, Madrid, 29-I-55).

62 «Repercusiones de la II Bienal en América», La Vanguardia, Barcelona, 16-VI-55 
que la siguió, realizada en Ginebra (Suiza), entre el 17 de marzo y el 6 de mayo de $1956{ }^{63}$.

La III Bienal, como las demás, no dejó de ser conflictiva en cuanto a la participación de los artistas, aunque, aparte de la expresión del rechazo en el extranjero, consiguió llevar a sus salas una representación de artistas mexicanos, incluso de artistas españoles exiliados y residentes en México y París. Además, a la par que expuso como «Precursores» a Picasso, José Clemente Orozco, Barradas, Torres-García, etc., haciendo gala de su amplio eclecticismo, aceptaba —con enfrentamiento muy comentado en la prensa- desde la figuración académica de un Togores a la pintura matérica de un Tàpies. Mientras, en otro orden, también supo añadir al

63 Fue esta III Bienal la mejor de todas las celebradas en cuanto a calidad de lo expuesto. Nuevamente, como en las anteriores ediciones, se sucedieron en su organización estatutos, convocatorias, juntas, jurados, exposiciones preparatorias, etc. Concurrieron a ella 944 artistas de 20 paises; hubo 1956 obras a concurso, 164 Salas Especiales y 50 obras del Legado Cambó expuestas en primicia. La ecléctica línea artística de las primeras Bienales intentó ser superada, auqneu pese al tono más avanzado siguió persistiendo como norma de selección. Fue, por otro lado, el momento de los premios concedidos a artistas españoles como Angel Ferrant, Pablo Serrano, Sebastián Badia, Rafael zabalete, Frncisco lozano, Antoni Tàjies, Manuel Capdevilla, Xavier

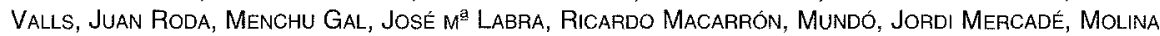
Sanchez, Vela Zanetti, Francisco Gali, Delly Tejero, Juan José Tharrats, José Hutuna, José Mª Bosch AYMerich, Muñox Monasterio, Robles Giménez, Antonio Perpiña, etc. y a artistas americanos como Oswaldo Guayasamín, Alejandro Obregón, Antonio Valencia, francisco Cárdenas, Fernando Botero, Judith Márquez, Cecilia Porras, Galo Gaecio, Bosch Roger, Rosado, José Echeve, Magdaleno, De la Mora, Javier Busquet, Franz Heet, etc. Asimismo añadamos que esta II) Bienal supo rodearse de importantes incentivos y atractivos complementarios, pues al concurso se sumó un Festival de Documentales de Arte, una interesante selección de los fondos del Museum of Modern Art de Nueva York, la exposición «Precursores y Maestros de la pintura y Escultura Contemporáneas", la muestra del VIII Salón de Octubre - habitualmente celebrado en las Galerías Layetanas-, la exposición del Legado Cambó, etc. Con todo, de la edición ha trascendido especialmente entre la historiografía española, quedando casi como un tópico en su caracterización, la aparición en ella del informalismo, singularmente de la mano de TÀPIES, que presentó entonces algunas de sus más recientes pinturas matéricas, auqneu en conjunto la Bienal barcelonesa principalmente significó el triunfo en España de las tendencias abstractas y su pleno reconocimiento oficial. Finalmente, citemos entre los catálogos más interesantes a que dió lugar junto a sus muestras retrospectivas y antológicas: III Bienal Hispanoamericana de Arte. Catálogo Oficial. Barcelona, Palacio Municipal de Exposiciones, 24 de septiembre 1955-6 de Enero 1956, Barcelona, Imprenta Vélez, 1955; III Bienal Hispanoamericana de Arte. Precursores y mestros de la pintura y Escultura Contemporánea. Blanes, Blanes Viale, Bafradas, figari, Gargallo, hugue, Nonell, Olasagasti, Orozco, PIcasso, Rolg y TonRes Gaacía Barcelona, Imprenta Vélez, diciembre de 1955 (con introducciones a los artistas de Angel Marsá, lloréns artigas, Rafael Benet, Sánchez Camargo, Santos Torroella, Juan Cortés y José M $M^{\circledR}$ Sucre); III Bienal Hispanoamericana de Arte. 8 Salón de Octubre, Barcelona, Imp. Tharrats, 1955; III Bienal Hispanoamericana de Arte. El arte moderno en los Estados Unidos. Selección de las colecciones del Museum of Modern Art, Nueva York. Palacio de la Virreina y Museo de Arte Moderno. Barcelona 24 Septiembre-24 Octubre 1955, Barcelona, Industrias Gráficas Seix Barral Hnos., 1955; PiCASso et l'art contemporain Hispano-Americain. Picasso, Nonell, Manolo. Sélection de la Ille Biennale Hispano-Americaine. Genève, Musée d'Art et d'Histoire, du 17 Mars au 6 Mai 1956, Genève, Imp. Populaires, s/a. (1956). 
certamen perspectivas de nuevo cuño, como la celebración de un festival de Documentales de Arte o la exhibición de una selección de los fondos del MOMA de Nueva York, que lo prestigiaran y actualizaran; aunque su despliegue de actividades requirió de espacios materiales de celebración (aparte del Palacio Municipal de Exposiciones del Parque de la Ciudadela, donde se instaló la obra concursante), ampliando sus emplazamientos para las muestras complementarias al Palacio de la Virreina, la Capilla de Santa Agueda y el Salón Tinell.

Venezuela, por su parte, siguiendo el mismo ritmo que en las anteriores ocasiones, nuevamente volvió a concurrir al certamen, estando presente en todas sus secciones salvo las de Arquitectura, Joyería, esmaltes y orfebrería y las Salas Especiales, aunque no obtuvo galardones. Su aportación de dieciocho artistas y veintisiete obras, semejante a la de las otras ediciones, siguió también insistiendo en muchos de los mismos nombres y así en Barcelona estuvieron las obras, en la sección de Pintura, de Antonio Alcántara, Magda Andrade, Pablo Benavides, Manuel Cabré, Pedro Centeno, Juan Vicente Fabbiani, Francisco Fernández R.Z., Manuel Vicente Gómez, Pedro Angel Gónzalez, Pedro León Castro, César Prieto, Armando Reverón, Julio César Rovaina, Virgilio Tronpon y Oswaldo Vigas, en la de Pintura al Agua y al Pastel, de Pascual Navarro y Manuel Pérez, en la de Dibujo, de Armando Reverón y, en la de Escultura, de Jesús Sabater ${ }^{64}$. Había, pues, artistas que habían concurrido a las dos ediciones anteriores, como Alcántara, P.A. González, Manuel Pérez y Prieto, otros que repetían tras la edición de La Habana y su antológica caraqueña, como Magda Andrade, Cabré, Fabbiani, León Castro, Reverón y Vigas, y otros que concurrían por vez primera; mas esta aportación venezolana, que si bien añadía algún elemento más avanzado, en definitiva seguía insistiendo en la misma línea que las anteriores participaciones del país en la Bienal, no mereció pena ni gloria dignas de reseñarse.

64 Sólo se presentaba una obra de cada uno de ellos, salvo de ALCÁNTARA y PASCUAL NaVARRo (tres cada uno), Centeno, P.A. González, Vigas y Sabater (dos cada uno) y Armando Reverón quién, por cierto, ya había muerto en 1954, lo que nuevamente induce a pensar en la desgana de la selección y en ue se echara mano de la colección del Museo de Bellas Artes de Caracas- (una obra en Pintura y otra en Dibujo). Véase el catálogo oficial /// Bienal..., Op. cit., págs. 143-146. Por otro lado, las seis cajas conteniendo su aportación regresaron a Caracas en el vapor «Virginia de Churruca" el 17 de julio de 1956, haciéndose cargo de la factura del flete Barcelona - La Guaira el Instituto de Cultura Hispánica. (Véase Despacho nº 335 del embajador de España en Caracas de fecha 14-VII1-56. AMAE, Leg. R-4839, Exp. 9). 
